\title{
Photophysical Approach of Biological Active Benzofuran Derivatized Pyrrole with Green Synthesized Silver NPs Using C. Roseus Leaves: Computational and Spectroscopic Study
}

Shivaprasadagouda Patil

Karnatak University Dharwad

Mahanthesh M. Basanagouda

P C Jabin Science College

Sudhir M. Hiremath

JT College: Jagadguru Tontadarya College

Aishwarya Nadgir

Karnatak University Dharwad

Malatesh S Pujar

Karnatak University Dharwad

Raghavendra K. Sali

Karnatak University Dharwad

Ashok H Sidarai ( $\nabla$ ashok_sidarai@rediffmail.com )

Department of Physics, Karnatak University Dharwad, Karnataka, India. https://orcid.org/0000-00015673-4159

\section{Research Article}

Keywords: DPMA molecule, Solvatochromic shift Method, Dynamic quenching, Stern-Volmer Plot, HOMOLUMO structure, Molecular electrostatic potential

Posted Date: November 5th, 2021

DOl: https://doi.org/10.21203/rs.3.rs-999574/v1

License: (1) This work is licensed under a Creative Commons Attribution 4.0 International License.

Read Full License 


\title{
Photophysical approach of biological active benzofuran derivatized pyrrole
} with green synthesized silver NPs using C. roseus leaves: computational and spectroscopic study

Shivaprasadagouda Patil ${ }^{\mathrm{a}, \mathrm{d}}$, Mahanthesh M. Basanagouda ${ }^{\mathrm{b}}$, Sudhir M. Hiremath ${ }^{\mathrm{c}}$, Aishwarya Nadgir ${ }^{\mathrm{a}}$, Malatesh S Pujar ${ }^{\mathrm{a}}$, Raghavendra K.Sali ${ }^{\mathrm{a}, \mathrm{d}}$, Ashok H. Sidarai ${ }^{\mathrm{a}^{*}}$

${ }^{a}$ Department of Studies in Physics, Karnatak University, Dharwad-580003, Karnataka, India.

${ }^{\mathrm{b}}$ Department of Chemistry, K.L.E. Society's P.C. Jabin Science College, Hubballi-580031, Karnataka, India.

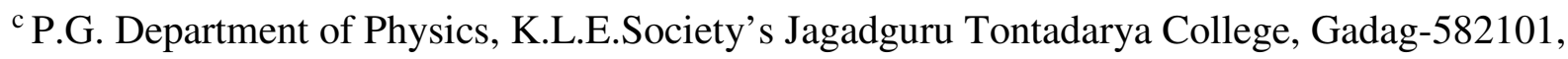
Karnataka, India.

${ }^{\mathrm{d}}$ Department of Physics, J.S.S.Arts, Science and Commerce College, Gokak-591307, Karnataka, India.

*Corresponding author email ID: $\underline{\text { ashok_sidarai @ rediffmail.com }}$

\begin{abstract}
The electronic absorption and fluorescence emission spectra of N-(2,5-dimethyl-pyrrol-1-yl)-2(5-methoxybenzofuran-3-yl)acetamide (DPMA) molecule were recorded in various solvents at room temperature with the aim of estimation of ground state $\left(\mu_{g}\right)$ and excited states $\left(\mu_{e}\right)$ dipole moments using Lippert's, Bakshiev's and Kawski-Chamma-Viallete's equations. The results were signified that, the excited state dipole moment is greater than the ground state dipole moment, which indicates the excited state dipole moment is more polar than the ground state dipole moment. Ecofriendly green synthesis of silver nanoparticles (Ag NPs) were synthesized using catharanthus roseus (C.R) leaf extract was done. These synthesized Ag NPs were used as
\end{abstract}


fluorescence quenchers. Fluorescence lifetime measurement is carried out using time correlated single photon counting technique of DPMA molecule with various concentrations of Ag NPs. A linear Stern-Volmer (S-V) plot was obtained in steady state and transient state method. Furthermore we have estimated computational calculations such as ground state optimized geometry, molecular electrostatic potential (MEP), highest occupied molecular orbital (HOMO), lowest unoccupied molecular orbital (LUMO), experimental and theoretical energy band gap, solvent polarity and normalized solvent polarity values. Morphology and sizes of green synthesized silver NPs were characterized by transmission electron microscopy (TEM) with energy dispersive X-ray spectroscopy (EDX) and also characterized by UV-Visible absorption.

Keywords DPMA molecule; Solvatochromic shift Method; Dynamic quenching; Stern-Volmer Plot; HOMO-LUMO structure; Molecular electrostatic potential

\section{Introduction}

The N-(2,5-dimethyl-pyrrol-1-yl)-2-(5-methoxybenzofuran-3-yl)acetamide (DPMA) is a benzofuran derivatized pyrrole. Benzofuran is a bicyclic oxygenated heterocycle composed of fusion of benzene and furan rings. The benzofuran derivatives are commonly found in pharmaceuticals. Several studies have shown that benzofuran compounds exhibit significant role in biological activities such as anti-microbial, anti-tumor, anti-oxidative, anti-viral, anti-HIV and hepatitis $\mathrm{C}$ virus inhibitory activities [1-6]. The properties of benzofuran derivative are well recognized in electrochemical behavior, thermal stability [7], high fluorescence and quantum yields using solvatochromic method [8], electroluminescent material for emitting blue light [9], and fluorescent probe to optimize linear and non-linear optical properties [10]. 
Pyrrole derivatives are recognized as one of the very important classes of nitrogen heterocycles due to diverse chemical, biological and physical properties. The derivatives of pyrrole are widely used as intermediates in synthesis of several pharmaceuticals, medicines, agrochemicals, dyes, photographic chemicals [11]. Recently, Bulumulla et.al., reviewed the synthesis of pyrrole containing semiconducting materials and their applications in organic photovoltaics and organic field-effect transistors [12]. The derivatives of pyrrole have been explored as photoactive material in optical thermometry and thermography [13], fluorophores [14,15], photovoltaics [16], photochromism [17], luminescent and display materials [18], solar cells [19,20], semiconductors [21,22], fluorescent probes [23], molecules with NLO properties [24], optoelectronic applications due to structural modification of $\pi$-acceptors [25], absorption, fluorescence, phosphorescence and quantum yields [26], because of their inherent photophysical characteristics. These are also used as electric and optical sensor material for $\mathrm{pH}$ detection [27], optical chemosensor for $\mathrm{Cu}^{2+}$ and sensor for pyrophosphate [28], in electropolymerization [29]. The highly fluorescent materials with extended $\pi$-conjugation continue to attract much interest because of their applications as sensors and biosensors, electroluminescent materials, lasers and other optoelectronic devices [30-34].

Catharanthus roseus (C.R) is originated at the Indian Ocean Island of Madagascar country in East Africa. This plant does not require too much of water and nutrition, which is globally found in tropical areas especially in Southern Asia. It has immense ayurvedic medicinal values in its roots, leaves, stem and flowers. Whereas antioxidant property found in roots [35], antidiabetic [36], antimicrobial [37] and antiplasmodial [38] activities found in leaves.

This paper reports estimation of ground state and excited state dipole moments of DPMA molecule using solvatochromic shift method, analysis of microscopic solvent polarity $\left(E_{T}^{N}\right)$ and 
fluorescence quenching and fluorescence lifetime of biologically active DPMA molecule using Ag NPs by catharanthus roseus (C.R) leaf extract. Herein we are also report the green synthesis of Ag NPs and used as fluorescence quenchers.

\section{Experimental}

\section{Materials and Methods}

The required N-(2,5-dimethyl-pyrrol-1-yl)-2-(5-methoxybenzofuran-3-yl)acetamide (DPMA) molecule was prepared as described in our previous work [39]. The molecular structure of the DPMA is shown in Fig 1. The $\mathrm{AgNO}_{3}$ and solvents used for the present investigation were 1,4-dioxane, acetonitrile, butan-2-ol, chloroform, dimethyl formamide (DMF), dimethyl sulphoxide (DMSO), ethanol, ethyl acetate, methanol, propane-2-ol, toluene and were obtained from S.D Fine Chemicals Ltd. India, all these solvents were of spectroscopic grade and used without further purification. All the measurements were carried out at room temperature keeping a DPMA concentration at $1 \times 10^{-6} \mathrm{M}$. In order to prepare quencher, we used Ag NPs in $5 \mathrm{~mL}$ of ethanol solvent. The concentration of solute DPMA is fixed i.e., $1 \times 10^{-4} \mathrm{M}$. and varied the $\mathrm{Ag}$ NPs concentration $0.0 \times 10^{-5} \mathrm{M}, 0.2 \times 10^{-5} \mathrm{M}, 0.4 \times 10^{-5} \mathrm{M}, 0.6 \times 10^{-6} \mathrm{M} 0.8 \times 10^{-6} \mathrm{M}$ and $1.0 \times 10^{-6}$ M.

\section{Spectroscopic method}

Absorption and fluorescence spectra were recorded on a UV-Visible spectrophotometer (Hitachi U3310, Japan) and fluorescence spectrophotometer (Hitachi F-7000, Japan), respectively at room temperature. 


\section{Computational method}

The complete computational studies are performed using Gaussian 09w software along with DFT method and B3LYP/6-311++G (d, p) basis set [40]. Gauss View 5.0 software [41] is used to visualization of the molecule. Highest occupied molecular orbital (HOMO) represent electron donating ability of the molecule and lowest unoccupied molecular orbital (LUMO) represents electron accepting ability of the molecule. MEP map gives the valuable information about the shape, size and charge region present in the molecule and also provides the net electrostatic effect caused by the total charge distribution.

\section{Solvatochromic shift method}

By taking into the account of simplest quantum-mechanical second order perturbation theory of absorption maxima $\left(\overline{v_{a}}\right)$ and emission maxima $\left(\overline{v_{f}}\right)$ (in wavenumbers), band shifts of spherical solute molecule in different solvents of varying dielectric constant $(\varepsilon)$ and refractive index $(n)[42]$.

$\overline{v_{a}}-\overline{v_{f}}=S_{1} F(\varepsilon, n)+$ Constant

$\left(\overline{v_{a}}-\overline{v_{f}}\right)$ is Stoke shift and $F(\varepsilon, n)$ is the solvent polarity function, the graph $\left(\overline{v_{a}}-\overline{v_{f}}\right)$ vs. $F(\varepsilon, n)$ will get the $\mathrm{S}_{1}$

Lippert's polarity function is given by

$$
F(\varepsilon, n)=\left[\frac{\varepsilon-1}{2 \varepsilon+1}-\frac{n^{2}-1}{2 n^{2}+1}\right]
$$

$\overline{v_{a}}-\overline{v_{f}}=S_{2} F(\varepsilon, n)+$ Constant $[43]$

Bakshiev's Polarity function $F_{1}(\varepsilon, n)$ is given by 


$$
F_{1}(\varepsilon, n)=\frac{2 n^{2}+1}{n^{2}+2}\left[\frac{\varepsilon-1}{\varepsilon+2}-\frac{n^{2}-1}{n^{2}+2}\right](3)
$$

Kawski-Chamma-Viallete's polarity function is given by $F_{2}(\varepsilon, n)$ [44].

$$
\begin{aligned}
& F_{2}(\varepsilon, n)=\left[\frac{2 n^{2}+1}{2\left(n^{2}+2\right)}\left(\left[\frac{\varepsilon-1}{\varepsilon+2}-\frac{n^{2}-1}{n^{2}+2}\right]+\frac{3\left(n^{4}-1\right)}{2\left(n^{2}+2\right)^{2}}\right)\right] \\
& S_{1}=\left[\frac{2\left(\mu_{e}-\mu_{g}\right)^{2}}{h c a^{3}}\right] \\
& S_{2}=\left[\frac{2\left(\mu_{e}-\mu_{g}\right)^{2}}{h c a^{3}}\right] \\
& S_{3}=\left[\frac{2\left(\mu_{e}^{2}-\mu_{g}^{2}\right)}{h c a^{3}}\right]
\end{aligned}
$$

Here $S_{1}, S_{2}$ and $S_{3}$ are the slope values using the Lippert's (5), Bakshiev's (6) and Kawski-ChammaViallete's (7) equations. Where $\mu_{g}$ and $\mu_{e}$ are the ground state and excited state dipole moments, $h$ is the Planck's constant, $c$ is the velocity of light in vacuum, $a$ is the Onsager cavity radius of the solute molecule and the value was calculated by atomic increment method by Edward [45] and also determined by molinspiration application,

$$
\begin{aligned}
& \mu_{g}=\frac{S_{3}-S_{2}}{2}\left[\frac{h c a^{3}}{2 S_{2}}\right]^{\frac{1}{2}} \\
& \mu_{e}=\frac{S_{3}+S_{2}}{2}\left[\frac{h c a^{3}}{2 S_{2}}\right]^{\frac{1}{2}}
\end{aligned}
$$


Eq. (9) is dividing by Eq. (8)

$$
\frac{\mu_{e}}{\mu_{g}}=\left[\frac{S_{3}+S_{2}}{S_{3}-S_{2}}\right] \text { for } S_{3}>S_{2}(10)
$$

\section{Fluorescence quenching}

Fluorescence quenching is the phenomena of decrease in the fluorescence intensity of a sample. This includes exited-state reactions, molecular re-arrangements, energy transfer, ground state complex formation and collisional quenching [46]. Fluorescence quenching of organic molecules in solvents carried out by using different solvents i.e. aniline [47] and carbon tetrachloride [48]. In recent years chemically and green synthesized nanoparticles were also used as quenchers i.e. $\mathrm{TiO}_{2}$ [49], $\mathrm{Ag}$ [50], $\mathrm{ZnS}$ [51], $\mathrm{ZnO}$ [52][53] NPs.

The fluorescence emission spectrum of DPMA molecule in ethanol solvent is recorded by absorption of maximum wavelength i.e. $293 \mathrm{~nm}$. The fluorescence spectrum of DPMA molecule of various concentrations of Ag NPs has been studied. The intensity is decreases with increase in concentration of Ag NPs. Furthermore we have studied fluorescence lifetime study by the instrument time correlated single photon counting (TCSPC) technique, 1,4-Dioxane and ethanol solvents were used in DPMA molecule in presence of various concentration of Ag NPs, fluorescence lifetime of the DPMA molecule decreases when increase the concentration of Ag NPs.

\section{Stern -Volmer Equation}

For steady state

$$
\frac{F_{O}}{F}=1+K_{S V}[\mathrm{~A} g](9)
$$

For Transient state 


$$
\frac{\tau_{0}}{\tau}=1+K_{S V}[A g]
$$

Where $F_{O}$-Fluorescence intensity of solute without quencher

$F$ - Fluorescence intensity of solute with quencher

$\tau_{0}$ - Fluorescence lifetime of solute without quencher

$\tau$-Fluorescence lifetime of solute with quencher

[Ag] - Concentration of Ag NPs.

\section{Green synthesis method}

\section{Preparation of C.roseus leaves extract solution}

Fresh leaves of C. roseus (C.R) were collected from Karnatak University, Dharwad. The C.R leaf extract solution was prepared by using $15 \mathrm{~g}$ of C.R leaves, rinsed and washed with deionized water. The same amount of C.R leaves cut into small pieces, the chopped C.R leaves were mixed with $100 \mathrm{~mL}$ of distilled water and heated for 15 minute. The cooled leaf broth solution was filtered through Whatman filter paper and stored in ice cubes.

\section{Green synthesis of Ag Nanoparticles}

Green synthesis of Ag NPs has been carried out based on the literature with some modification [54]. The $10 \mathrm{~mL}$ of C.R leaves extract solution was added drop-wise to $0.01 \mathrm{M}$ of $\mathrm{AgNO}_{3}$, which was prepared in $10 \mathrm{~mL}$ of distilled water. This mixture was stirred well with the help of magnetic stirrer for 5 minutes, color changes from pale yellow to dark brown indicating the formation of Ag NPs as shown in Fig 2. This mixture was added in $50 \mathrm{~mL}$ of Teflon made autoclave which was heated to $160^{\circ} \mathrm{C}$ for 6 hours, and then cooled to room temperature. After 
collecting the mixture from autoclave, separation was done by the centrifuging at the rate of $3000 \mathrm{rpm}$ for 15 minute, the Ag NPs were obtained.

\section{ET (30) solvent polarity and $E_{T}^{N}$ normalized solvent polarity of solvents}

Here $\mathrm{E}_{\mathrm{T}}(30)$ and $\mathrm{E}_{\mathrm{T}}^{\mathrm{N}}$ were solvent polarity and normalized solvent polarity. $\mathrm{E}_{\mathrm{T}}(30)$ i.e. calculated solvent polarity values were obtained based on the maximum absorption of the DPMA molecule dissolved in various solvents using equation (10).

The solvent polarity $\mathrm{E}_{\mathrm{T}}(30)$ and normalized solvent polarity $\left(E_{T}^{N}\right)$ values are given in Table 3

$\mathrm{E}_{\mathrm{T}}(30)=h c \vartheta_{\max } \times N_{A}=\left(2.8591 \times 10^{-3}\right) \vartheta_{\max }\left(\mathrm{cm}^{-1}\right)=28591 / \lambda_{\max }(\mathrm{nm})$

$\mathrm{E}_{\mathrm{T}}(30)=\frac{28591}{\lambda_{a} \max (\mathrm{nm})}\left(\mathrm{kcal} \mathrm{mol}^{-1}\right)$

$E_{T}^{N}=\frac{\left.E_{T} \text { (solvent }\right)-E_{T}(T M S)}{E_{T}(\text { water })-E_{T}(T M S)}=\frac{\left.E_{T} \text { (solvent }\right)-30.7}{63.1-30.7}=\frac{E_{T}(\text { solvent })-30.7}{32.4}$

$\mathrm{E}_{\mathrm{T}}^{\mathrm{N}}$ values have been defined based on the equation (11) using water and tetramethylsilane (TMS) as most polar and least polar, respectively. Therefore $\mathrm{E}_{\mathrm{T}}^{\mathrm{N}}$ scale ranges from 0.00 for TMS to 1.00 for water [55-56].

\section{Results and Discussion}

The DPMA was dissolved in various solvents i.e.1,4-dioxane, acetonitrile, chloroform butan-2-ol, DMF, DMSO, ethanol, ethyl acetate, methanol, THF, and toluene. The Fig 3 and Fig 4 represents the maximum absorption and maximum emission of wavelengths, respectively, in various solvents. These wavelengths were converted into wavenumbers $\left(\mathrm{cm}^{-1}\right)$, the difference between maximum absorption and maximum emission is known as Stoke shift as shown in Table 1. 
DPMA molecule interacts with various solvents, considering their refractive index $(n)$ and dielectric constant $(\varepsilon)$ which was used in polarity functions $F(\varepsilon, n), F_{1}(\varepsilon, n), F_{2}(\varepsilon, n)$ of Lippert's, Bakshiev's and Kawski-Chamma-Viallete's equations by solvatochromic shift method is shown in Table 2. The graphs $F(\varepsilon, n) \mathrm{Vs} .\left(\overline{v_{a}}-\overline{v_{f}}\right), F_{1}(\varepsilon, n) \mathrm{Vs} .\left(\overline{v_{a}}-\overline{v_{f}}\right), F_{2}(\varepsilon, n) \mathrm{Vs} .\left(\frac{\overline{v_{a}}+\overline{v_{f}}}{2}\right)$ and $E_{T}^{N}$ Vs. $\left(\overline{v_{a}}-\overline{v_{f}}\right)$ found to be near linear coefficients as shown in Fig 5. The absorbance wavelength of a molecule is inferred to $\pi-\pi^{*}$ transition experienced with bathochromic shift with increasing polarity of the solvent, correlations of Lippert's, Bakshiev's and Kawski-Chamma-Viallete's slopes, intercept and correlation coefficient values represent in Table 3. Estimation of ground state and excited state dipole moments, were calculated by Lippert's, Bakshiev's and Kawski-ChammaViallete's equations displayed in Table 4. The $\lambda_{a}, \mathrm{E}_{\mathrm{T}}(30)$ and $\mathrm{E}_{\mathrm{T}}^{\mathrm{N}}$ results are summarized in Table 5. $\mathrm{E}_{\mathrm{T}}^{\mathrm{N}}$ versus $\overline{v_{a}}-\overline{v_{f}}\left(\mathrm{~cm}^{-1}\right)$ the graphs shows good correlation coefficient (r) were found to be linear. The emission spectra of DPMA molecule in ethanol solvent for different concentration of Ag NPs i.e. $0.0 \times 10^{-5} \mathrm{M}, 0.2 \times 10^{-5} \mathrm{M}, 0.4 \times 10^{-5} \mathrm{M}, 0.6 \times 10^{-6} \mathrm{M} 0.8 \times 10^{-6} \mathrm{M}$ and $1.0 \times 10^{-6} \mathrm{M}$. were recorded and observed that by adding different concentration of Ag NPs in DPMA molecule, the fluorescence intensity decreases with increase in concentration of Ag NPs as shown in Fig 6. This conclusion states that fluorescence quenching of DPMA molecule using Ag NPs is purely dynamic. The graph $\frac{F_{O}}{F} \mathrm{Vs}[\mathrm{Ag}]$ were plotted steady state method according Stern-Volmer equation (9) is found to be linear as shown in Fig 7. Fluorescence lifetime of DPMA molecule of various concentration of Ag NPs using Stern -Volmer equation called transient state method i.e. $\frac{\tau_{0}}{\tau} \mathrm{Vs}_{s}$ [Ag] graphs were plotted using 1,4-dioxane and ethanol solvents as shown in Fig 8. Results were found to be good correlation co-efficient and linear. The fluorescence life time decay curves of 
DPMA molecule using the solvents of 1,4-dioxane and ethanol solvents for various concentration of Ag NPs i.e. $0.0 \times 10^{-5} \mathrm{M}, 0.2 \times 10^{-5} \mathrm{M}, 0.4 \times 10^{-5} \mathrm{M}, 0.6 \times 10^{-6} \mathrm{M} 0.8 \times 10^{-6} \mathrm{M}$ and $1.0 \times 10^{-6}$ ,increase in concentration of Ag NPs, fluorescence lifetime decreases of DPMA molecule, as shown in Fig 9.

\section{Optical band gap}

The optical band gap $\left(\mathrm{E}_{\mathrm{opt}}\right)$ of the DPMA molecule was determined by UV-Visible spectrophotometer. The DPMA molecule get energy by the absorption of UV-visible radiation and go through transition from lower energy state to the higher energy state. Optical band gap corresponds to the long wavelength edge of the excitation absorption band [57]. $\lambda_{\text {onset }}$ value for DMSO, ethyl acetate, 1,4-dioxane, butan-2-ol, chloroform solvents is found to be $312 \mathrm{~nm}$ and experimental optical band gap is $3.97 \mathrm{eV}$.

$$
E_{\text {gap }}^{\text {opt }}=\frac{1240}{\lambda_{\text {onset }}}
$$

\section{UV-Visible spectrum of Ag NPs}

UV-Visible spectrum of Ag NPs recorded in aqueous media, it is observed that silver surface plasmon resonance band occurs at $414 \mathrm{~nm}$. as shown in Fig $\mathbf{1 0}$ most of researchers have reported absorption spectra of Ag NPs between the range $410 \mathrm{~nm}-440 \mathrm{~nm}$ [58-59].

\section{Optimization process}

The optimization process gives the minimum energy confirmation of the structure. The title molecule is completely optimized by DFT method with B3LYP along with 6-311++G (d, p) basis level. The ground state optimized structure along with dipole moment is shown in Fig $\mathbf{1 1}$ and Gauss view optimized structure is presented in Fig 12. 


\section{Molecular Electrostatic Potential}

Molecular electrostatic potential (MEP) provides the necessary information regarding molecular size, shape, importantly positive, negative and neutral electrostatic potential areas are expressed in terms of color coding technique. Different values of the electrostatic potential are represented by various colors, red represents the most electrostatic negative potential, blue represents the region of most positive electrostatic potential and green represents the region of zero potential. The potential increases in the order of red $<$ orange $<$ yellow $<$ green $<$ cyan $<$ blue $[60,61]$. Herein the color code lies between -0.02304 a.u (dark red) to 0.0240 a.u (dark blue) as shown in Fig 13. In the present molecule, highest electronegative region present around oxygen atom in the benzofuran ring. Second highest electronegative region present around the oxygen atom lies between the $\mathrm{CH}_{3}$ group and benzofuran ring. The highest electropositive region present around the hydrogen atoms present in $\mathrm{CH}_{2}$ group. Second highest electropositive region present around hydrogen atom attached to nitrogen atom.

\section{Frontier molecular orbital studies (FMO)}

Energies and distributions of the FMO are very important indicators of the reactivity. Highest occupied molecular orbital (HOMO) represent electron donating ability of the molecule and Lowest unoccupied molecular orbital (LUMO) represents electron accepting ability of the molecule [62].The kinetic stability of the molecule is indicated by HOMO-LUMO energy gap [63] and energy gap is obtained by energy difference between HOMO and LUMO. The energies of LUMO and HOMO and the related energy gaps are computed using optimized structure of the molecule. Fig.14 shows the two dimensional structure of the energy gaps between HOMO and LUMO. The energies of HOMO and LUMO are -5.59 and $-1.03 \mathrm{eV}$ respectively. The energy gap 
between HOMO-LUMO is $4.53 \mathrm{eV}$. The small energy gap obtained represents more polarizability and so this chalcone predicted promising NLO properties. The ionization potential and chemical hardness and other properties are estimated using Koopman's theorem [64]. Generally large energy gap indicates that, molecule is hard and stable, whereas the small energy gap indicate that molecule is soft and reactive. The energy gap of the DPMA is $4.53 \mathrm{eV}$. Hence the molecule is soft and reactive.

\section{TEM-EDX analysis of Ag nanoparticles}

Morphological nature of the bio-synthesized Ag NPs is studied with Transmission electron microscopy (TEM). Here we observed the monodispersed spherical nature of the Ag NPs. Due to some bioactive molecule, there is agglomeration between some particles but all are in similar size in the range of $20 \mathrm{~nm}-40 \mathrm{~nm}$. The average size of synthesized Ag NPs is around $28 \mathrm{~nm}$. This regularity in particles size is due to the phytoconstituent residual present in the C.R leaves, this act as capping agent for the growth of the nanoparticle. The Fig 15 (a) depicts the TEM image of Ag NPs of scale range $100 \mathrm{~nm}$ and $20 \mathrm{~nm}$ in (b), in (c) showing the selected area electron diffraction (SAED). In SAED pattern we observed the bright spots and less intensive rings. The bright spots reveal the sharp and crystalline nature of the NPs and the green synthesized Ag NPs are very small in size so we did not get the bright rings here, d-spacing values are obtained by the help of imageJ application. Further using these values, we can predict the h,k,l values by comparing with reported literature [65-68]. Along with TEM we performed the EDX to reconfirm our Ag NPs. As shown in Fig 16 represents the EDX spectrum of synthesized Ag NPs. Herein, we observed the necessary Ag with atomic and weight of $100 \%$ each. 


\section{Conclusion}

In summary photophysical study of benzofuran derivatized pyrrole (DPMA), estimated the ground and excited state dipole moments using solvatochromic shift method, which involves Lippert's, Bakshiev's and Kawski-Chamma-Viallete's equations. The result indicated that excited state dipole moment is greater than ground state dipole moment. The solute solvent interaction of DPMA molecule leads to $\pi$ to $\pi^{*}$ transition. Further, synthesized Ag NPs using C.R leaves extract are used as fluorescence quencher. Fluorescence intensity of DPMA molecule decreases with increasing the concentration of Ag NPs and obtained the S-V plot found to be linear. Fluorescence lifetime of DPMA molecule using S-V plot equation of transient state method using 1,4-dioxane and ethanol solvents were found to be linear and near to the correlation coefficient value. Fluorescence lifetime decreases with increase the concentration of Ag NPs concentration. The size, morphology and elemental composition of Ag NPS were determined by TEM with EDX. Further we conclude that computational calculations of optimized geometry structure, molecular electrostatic potential (MEP), HOMO, LUMO of DPMA molecule, experimental and computational energy band gap is $3.97 \mathrm{eV}$ and $4.53 \mathrm{eV}$. DFT calculations are done by the Gaussian-09 basic set (B3LYP/6-311G)

\section{Acknowledgement}

The SP author is grateful to the technical staff of USIC, Karnatak University, Dharwad for recording the data of absorption and emission spectra 


\section{Author declarations}

\section{Funding}

Not applicable

\section{Conflict of Interest}

Not applicable

\section{Ethics Approval}

This is to certify that entitled "Photophysical approach of biological active benzofuran derivatized pyrrole with green synthesized silver NPs using C. roseus leaves: computational and spectroscopic study" submitted by Dr Ashok H Sidarai et al.,for the publication in Journal of Fluorescence is based on original work results of the experiments were carried out by all the authors in my supervision. This article has not been submitted to any other journals.

\section{Corresponding Author}

Dr. Ashok H Sidarai

\section{Consent to participate}

Not applicable

\section{Consent to publication}

Not applicable

\section{Code availability}


Not applicable

\section{Author's contribution}

Shivaprasadagouda Patil: Conceptualization, Investigation, analysis of data and draft

Mahanthesh M. Basanagouda, Sudhir M. Hiremath, Aishwarya Nadgir, Malatesh S Pujar, and Raghavendra K.Sali: Methodology, Investigation, Validation and Review Dr. Ashok H. Sidarai: editing, project administration and supervision of the work.

\section{References}

[1] H. Khanam, S. Uzzaman, Bioactive benzofuran derivatives: a review, Eur. J. Med. Chem. 97 (2014) 483-504.

[2] K.M Dawood, Benzofuran derivatives: a patent review. Expert OpinTher Patents 23 (2013) 1133-1156.

[3] A. Radadiya, Shah, A Bioactive benzofuran derivatives: an insight on lead developments, radioligands and advances of the last decade, Eur. J. Med. Chem. 97 (2015) 356-376.

[4] R. Naik, D.S.Harmalkar, X.Xu, K.Jang,K.Lee,Bioactive benjofuran derivatives:moracins A-Z in medicinal chemistry, Eur.J.Med.Chem.90 (2015) 379-393.

[5] H. Khanam, Shamsuzzaman bioactive benzofuran derivatives: a review, Eur. J. Med. Chem. 97(2015)483-504.https://doi.org/10.1016/j.ejmech.2014.11.039

[6] A. Hiremethad, M.R. Patil, K. R Chetana, K. Chand, A. Santos, R. S Keri Benzofuran, An emerging scaffold for antimicrobial agents, RSC Adv. 5 (2015) 96809-96828.

[7] J. Xu, G. Nie, S. Zhang, X. Han, S. Pu, L. Shen, Q. Xiao, Electrosyntheses of poly(2,3benzofuran) films in boron trifluoride diethyl etherate containing poly(ethylene glycol) oligomers, Eur. Polym. J. 41 (2005) 1654-1661.

[8] Sun YY, Liao JH, Fang JM ,Chou PT, Shen CH et.al(2006) Fluorescent organic nanoparticles of benzofuran-naphthyridine linked molecules: formation and fluorescence Enhancement in a aqueous media.Org.Lett 8:3713-3716 
[9] J.R. Hwu, K.S. Chuang, S.H. Chuang, S.C. Tsay, New Benzo[b]furans as Electroluminescent Materials for Emitting Blue Light, Org. Lett. (2005), 7, 1545-1548. https://doi.org /10.1021/o1050196d

[10] Przemysław Krawczyk modulation of benzofuran structure as a fluorescent probe to optimize linear and non-linear optical properties and biological activities Journal of Molecular Modeling (2020) 26: 272 https://doi.org/10.1007/s00894-020-04539-6.

[11] K.N. Chethan Prathap, P. Shalini, N.K. Lokanath, Synthesis, characterization, crystal structure, Hirshfeld surface analysis and DFT calculations of two novel pyrrole derivatives, Journal of Molecular Structure 1199 (2020) 127033.

[12] C. Bulumulla, R. Gunawardhana, P.L Gamage, J.T. Miller, R.N. Kularatne, M.C. Biewer, M.C. Stefan, Pyrrole-containing semiconducting materials: synthesis and applications in organic photovoltaics and organic field-effect transistors, ACS Appl. Mater. Interfaces 2020, 12 (2020) 32209-32232.

[13] A.K.A. Almeida, M.P. Monteiro, J.M.M. Dias, L. Omena, A.J.C. da Silva, J. Tonholo, R.J. Mortimer, M. Navarro, C. Jacinto, A.S. Ribeiro, I.N. de Oliveira, Synthesis and spectroscopic characterization of a fluorescent pyrrole derivative containing electron acceptor and donor groups, Spectrochimica Acta Part A: Molecular and Biomolecular Spectroscopy 128 (2014) 812-818.

[14] C.S. Li, Y.H. Tsai, W.C. Lee, W.J. Kuo, Synthesis and photophysical properties of pyrrole/polycyclic aromatic units hybrid fluorophores, J. Org. Chem. 75 (2010) 40044013.

[15] E.Y. Schmidt, N.V. Zorina, M.Y. Dvorko, N.I. Protsuk, K.V. Belyaeva, G.Clavier, R.M. Renault, T.T. Vu, A.I. Mikhaleva, Boris A. Trofimov, A general synthetic strategy for the design of new BODIPY fluorophores based on pyrroles with polycondensed aromatic and metallocene substituents, Chem. Eur. J. 17 (2011) 3069 -3073.

[16] B.M. Williams, V. Barone, B.D. Pate, J.E. Peralta, Gradient copolymers of thiophene and pyrrole for photovoltaics, Computational Materials Science 96 (2015) 69-71.

[17] R. Wang, X. Zhang, S. Pu, G. Liu, Y. Dai, Substituent effect in the photochromism of two isomeric asymmetric diarylethenes having pyrrole and thiophene units, Spectra Chimica Acta A 173 (2017) 257-263. 
[18] M. Zhang, X. Bu, T. Liu, W. Guo, H. Wang, Z. Zeng, Adjustable 2-cyano-3,4-difluoro1H-pyrrole-based luminescent liquid crystals: synthesis, properties and substituent effect, J. Mol.Liq. 264 (2018) 425-430.

[19] W. Gao, J.Wang, Y.Lin, Q. Luo, Y. Ma, J. Dou, H. Tan, C.Q. Ma, Z. Cui, Functionalization of diketopyrrolopyrrole with dendritic oligothiophenes: synthesis, photophysical properties, and application in solar cells, Journal of Photochemistry and Photobiology A: Chemistry 355 (2018) 350-359.

[20] M. Akram, S.A. Siddique, J. Iqbal, R. Hussain, M.Y. Mehboob, M.B.A.Siddique, S. Naveed, B. Ali, A. Hanif, M. Sajid, S. Shoukat, End-capped engineering of bipolar diketopyrrolopyrrole based small electron acceptor molecules for high performance organic solar cells, Computational and Theoretical Chemistry, 1201 (2021) 113242.

[21] O. Monroy, L. Fomina, M. E. Sanchez-Vergara, R. Gavino, A. Acosta, J.R. Alvarez Bada, R. Salcedo, Synthesis, characterization and semiconducting behavior of N,2,5trisubstituted pyrroles, J. Mol. Str. 1171 (2018) 45-53.

[22] G.A.V. Hernandez, R.D. Cruz, M.E.S.Vergara, L. Fomina, V.G. Vidales, B.1. Mora, A. Acosta, C. Ríos, R. Salcedo, New 2, 5-aromatic disubstituted pyrroles, prepared using diazonium salts procedures, J. Mol. Str. 1233 (2021) 130107.

[23] R. Shinotsuka, T. Oba, T. Mitome, T. Masuya, S. Ito, Y. Murakami, T. Kagenishi, Y. Kodama, M. Matsuda, T. Yoshida, M. Wakamori, M. Ohkura, J. Nakai, Synthesis of quinolyl-pyrrole derivatives as novel environment-sensitive fluorescent probes, Journal of Photochemistry \& Photobiology A: Chemistry 382 (2019) 111900.

[24] Kishor G. Thorat and Nagaiyan Sekar, Pyrrole-thiazole based push-pull chromophores: an experimental and theoretical approach to structural, spectroscopic and NLO properties of the novel styryl dyes, J. Photochem. Photobio, 2017, 333, 1-17.

[25] A.P. Bella, M. Panneerselvam, S.A. Vedha, M.Jaccob, R.V. Solomon, J.P. Merlin, DFTTDDFT framework of diphenylamine based mixed valence compounds for optoelectronic applications-structural modification of $\pi$-acceptors, Computational Materials Science 162 (2019) 359-369.

[26] J.Pina, D. Pinheiro, B. Nascimento, M. Pineiro, J. S. Seixas de Melo, The effect of polyaromatic hydrocarbons on the spectral and photophysical properties of diaryl-pyrrole 
derivatives: an experimental and theoretical study, Phys. Chem. Chem. Phys., 16 (2014) 18319-18326.

[27] K. Xie, N. An, Y. Zhang, G. Liu, F. Zhang, Y. Zhang, F. Jiao, Two-dimensional porphyrin sheet as an electric and optical sensor material for $\mathrm{pH}$ detection: A DFT study, Computational Materials Science 174 (2020) 109485.

[28] W.W. Wang, Y. Wang, W.N. Wu, X.L. Zhao, Z.Q. Xu, Z.H. Xu, X.X. Li, Y.C. Fan, Pyrrole-quinazoline derivative as an easily accessible turn-off optical chemosensor for $\mathrm{Cu} 2 \mathrm{p}$ and resultant $\mathrm{Cu} 2 \mathrm{p}$ complex as a turn-on sensor for pyrophosphate in almost neat aqueous solution, Spectrochimica Acta Part A: Molecular and Biomolecular Spectroscopy 226 (2020) 117592.

[29] M. Senel, M. Dervisevic, L. Esser, E. Dervisevic, J. Dyson, C.D. Easton, V.J. Cadarso, N.H. Voelcker, Enhanced electrochemical sensing performance by in situ electropolymerisation of pyrrole and thiophene-grafted chitosan. Int J Biol Macromol 143 (2020) 582-593.

[30] M.A. Thompson, S.R. Forrest, Nature 403 (2000) 750-751.

[31] B. Valeur, Molecular Fluorescence, Wiley-VCH, Weinheim, 2002.

[32] H. Jeong, H. Shin, J. Lee, B. Kim, Y.I. Park, K.S. Yook, B.K. An, J. Park, J. Photon. Energy 5 (2015) 057608.

[33] S. Kim, B. Kim, J. Lee, H. Shin, Y.I. Park, J. Park, Mat. Sci. Eng. R 99 (2016) 1-22.

[34] A. Airinei, R. Tigoianu, R. Danac, C. M. Al Matarneh, D.L. Isac, Steady state and time resolved fluorescence studies of new indolizine derivatives with phenanthroline skeleton, Journal of Luminescence 199 (2018) 6-12.

[35] R. Article, I nternational J ournal of Pharmacognosy and Chemistry, 1 (2020) 31-36.

[36] C.L.G. Don, Antidiabetic and Antioxidant Properties of Alkaloids from Catharanthus roseus (L.) G. Don, (2013) 9770-9784. https://doi.org/10.3390/molecules18089770.

[37] P.J. Patil, J.S. Ghosh, Antimicrobial Activity of Catharanthus roseus - A Detailed Study, 1 (2010) 40-44.

[38] S. Ponarulselvam, C. Panneerselvam, K. Murugan, N. Aarthi, K. Kalimuthu, S. Thangamani, Synthesis of silver nanoparticles using leaves of Catharanthus roseus Linn . 
G . Don and their antiplasmodial activities, Asian Pac. J. Trop. Biomed. 2 (2012) 574580. https://doi.org /10.1016/S2221-1691 (12)60100-2.

[39] V.S. Negalurmath, Synthesis of some heterocyclic compounds and study of their Biological activities, Doctoral dissertation, Karnatak University, Dharwad, India, 2019.

[40] M.J. Frisch, G.W. Trucks, H.B. Schlegel, G.E. Scuseria, M.A. Robb, J.R. Cheeseman, J.A. Montgomery Jr., T. Vreven, K.N. Kudin, J.C. Burant, J.M. Millam, S.S. Iyengar, J. Tomasi, V. Barone, B. Mennucci, M. Cossi, G. Scalmani, N. Rega, G.A. Petersson, H. Nakatsuji, M. Hada, M. Ehara, K. Toyota, R. Fukuda, J. Hasegawa, M. Ishida, T. Nakajima, Y. Honda, O. Kitao, H. Nakai, M. Klene, X. Li, J.E. Knox, H.P. Hratchian, J.B. Cross, C. Adamo, J. Jaramillo, R. Gomperts, R.E. Stratmann, O. Yazyev, A.J. Austin, R.Cammi, C. Pomelli, J.W. Ochterski, P.Y. Ayala, K. ] Morokuma, A. Voth, P. Salvador, J.J.Dannenberg, V.G. Zakrzewski, S. Dapprich, A.D. Daniels, M.C. Strain, O. Farkas,D.K. Malick, A.D. Rabuck, K. Raghavachari, J.B. Foresman, J.V. Ortiz, Q. Cui, A.G.Baboul, S. Clifford, J. Cioslowski, B.B. Stefanov, G. Liu, A. Liashenko, P. Piskorz, I.Komaromi, R.L. Martin, D.J. Fox, T.Keith, M.A. Al-Laham, C.Y. Peng, A. Nanayakkara, M. Challacombe, P.M.W. Gill, B. Johnson, W. Chen, M.W. Wong, C. Gonzalez, J.A. Pople, Gaussian Inc., Wallingford, CT, 2004.

[41] A.B. Nielsen, A.J. Holder, Gauss View 5.0 User's Reference, Gaussian Inc, Pittsburgh.

[42] V.R. Desai, M. Hunagund, S. Kadadevarmath, A.H. Sidarai, Solvent Effects on the Electronic Absorption and Fluorescence Spectra of HNP: Estimation of Ground and Excited State Dipole Moments, J. Fluoresc. 26 (2016) 1391-1400. https://doi.org /10.1007/s10895-016-1830-3.

[43] Bakshiev NG (1964) Universal intermolecular interactions and their effect on the position of the electronic spectra of the molecule in two component solutions. Opt Spectrosc $16: 821$

[44] Chamma A, Viallet PCR (1970) Determination of the dipole moment in a molecule in an excited singlet state. Acad Sci Parisb Serc 270:1901

[45] John T. Edward (1970) Molecular volumes and the Stokes-Einstein equation. J Chem Educ 47(4):261 
[46] Principles of Fluorescence Spectroscopy, Joseph R.Lakowicz Third edition Springer Publication

[47] A.H. Sidarai, V. R. Desai, S. M. Hunagund, M. Basanagouda and J. S. Kadadevarmath, "Effect of solvent polarity on the fluorescence quenching of TMC molecule by aniline in benzene-acetonitrile mixtures", Can. J. Phys.(2016) https://doi.org /10.1139/cjp-20160213.

[48] J. S. Kadadevarmath, G. H. Malimath, R. M. Melavanki and N. R. Patil, "Static and dynamic model fluorescence quenching of laser dye by carbon tetrachloride in binary mixtures", Spectrochimica Acta Part A.(2014), 117, 630.

[49] Vani R. Desai, Shirajahammad M. Hunagund et.al "Influence of concentrations of $\mathrm{TiO}_{2}$ nanoparticles on spectroscopic properties of a novel HMPP molecule" Journal of Molecular Liquids (2018) https://doi.org /10.1016/j.molliq.2018.09.134

[50] H.R.Deepa,H.M.Sureshkumar, M.Basanagouda and J.Thipperudrappa "Influence of Silver nanoparticles on absorption and fluorescence properties of laser dyes " Can. J. Phys. (2014) 92:163-167 dx.doi.org/10.1139/cjp-2013-0133

[51] D. Ayodhya, G. Veerabhadram, Green Synthesis, Optical, Structural, Photocatalytic, Fluorescence Quenching and Degradation Studies of ZnS Nanoparticles, J. Fluoresc. (2016) 2165-2175. https://doi.org /10.1007/s10895-016-1912-2.

[52] G. Venkatesan, R. Vijayaraghavan, S.N. Chakravarthula, G. Sathiyan, Fluorescent zinc oxide nanoparticles of Boswellia ovalifoliolata for selective detection of picric acid, 2 (2019) 1-7. https://doi.org /10.31716/frt.201902002.

[53] Shivaprasadagouda Patil, Vani R Desai, Mahantesha Basanagouda et.al Study of fluorescence quenching of benzofuran derivative using ZnO NPs: Solvent effect AIP Conference Proceedings 2244, 070038 (2020); https://doi.org/10.1063/5.0009154

[54] S. Ponarulselvam, C. Panneerselvam, K. Murugan, N. Aarthi, K. Kalimuthu, S. Thangamani, Synthesis of silver nanoparticles using leaves of Catharanthus roseus Linn . G . Don and their antiplasmodial activities, Asian Pac. J. Trop. Biomed. 2 (2012) 574580.https://doi.org /10.1016/S2221-1691 (12)60100-2.

[55] D.J. Eyckens, L.C. Henderson, L.C. Henderson, A Review of Solvate Ionic Liquids: Physical Parameters and Synthetic Applications, 7 (2019) 1-15. https://doi.org 10.3389/fchem.2019.00263. 
[56] C. Reichardt, Empirical Parameters of Solvent Polarity as Linear Free-Energy Relationships, Angew.Chem.Int.Ed.Engl.18 (1975) 98-110

[57] S. Patil, V.R. Desai, M.M. Basanagouda, S.M. Hunagund, Estimation of Photophysical and Electrochemical Parameters of Bioactive Thiadiazole Derivative, J. Fluoresc. 30 (2020) 741-750. https://doi.org /10.1007/s10895-020-02550-x.

[58] N. Swilam, K.A. Nematallah, A. Su, Y. Ting, J.E. Chin, Green way genesis of silver nanoparticles using multiple fruit peels waste and its antimicrobial, anti-oxidant and anti-tumor cell line studies (2017).IOP Conf. Series: Materials Science and Engineering 191 (2017) 012009 https://doi.org/10.1088/1757-899X/191/1/012009

[59] B. Seema, Green synthesis of nano silver particles from extract of Eucalyptus hybrid (safeda) leaf. Vol. 4, No. 3(2009) 537-543

[60] V. Sri, A. Pugazhendhi, K. Gopalakrishnan, Biofabrication and characterization of silver nanoparticles using aqueous extract of seaweed Enteromorpha compressa and its biomedical properties, Biotechnol. Reports. 14 (2017) 1-7. https://doi.org /10.1016/j.btre.2017.02.001.

[61] M. Raja, R.R. Muhamed, S. Muthu, M. Suresh, SC, Synthesis, spectroscopic (FT-IR, FT-Raman,NMR,UV-Visible),NLO,NBO,HOMO-LUMO, Fukui function and molecular docking study of (E)-1-(5-bromo-2- hydroxybenzylidene)semicarbazide J. Mol. Struct. (2017) https://doi.org /10.1016/j.molstruc.2017.03.117

[62] S.M. Hiremath, A. Suvitha, N.R. Patil, C.S. Hiremath, S.S. Khemalapure, S.K. Pattanayak, V.S. Negalurmath, K. Obelannavar, Molecular structure, vibrational spectra, NMR , UV , NBO , NLO ,HOMO-LUMO and molecular docking of 2- ( 4 , 6-dimethyl1- benzofuran-3yl ) acetic acid (2DBAA): Experimental and theoretical approach, J. Mol. Struct. 1171(2018) 362-374. https://doi.org /10.1016/j.molstruc.2018.05.109.

[63] S.M. Hiremath, A.S. Patil, C.S. Hiremath, M. Basanagouda, S.S. Khemalapure, N.R. Patil, S.B. Radder, S.J. Armaković, S.Armaković. Structural, spectroscopic characterization of 2-(5-methyl-1-benzofuran-3-yl) acetic acid in monomer, dimer and identification of specific reactive, drug likeness properties: experimental and computational study, J. Mol. Struct., 2019, 1178, 1-17.

[64] T. Koopmans, Über die Zuordnung von Wellenfunktionen und Eigenwertenzu den Einzelnen Elektronen Eines Atoms. Physica, 1934, 1, 104-113. 
[65] British Museum (Natural History) Dana's system of Mineralogy, 7th Edition,

[66] Hanawalt.et al., Anal. Chem., 10,475 the structure of crystals, 1st Ed.,(1938)

[67] Standke,B.,Jansen,M.,Z.Anarg.Allg.chem.,535,39, (1986)

[68] Davey.,Phys.Rev.,25,753, Archs. Sci. Geneve (1925)

Table 1. Solvents behavioral spectra and calculated their polarity functions polarity function of Lippert's, Bakshiev's, KCV, empirical state parameter used for finding the dipole of molecule.

\begin{tabular}{|l|l|l|l|l|l|}
\hline Solvents & $\begin{array}{l}\text { Dielectric } \\
\text { constant } \\
(\varepsilon)\end{array}$ & $\begin{array}{l}\text { Refractive } \\
\text { Index }(n)\end{array}$ & $F(\varepsilon, n)$ & $F_{1}(\varepsilon, n)$ & $F_{2}(\varepsilon, n)$ \\
\hline 1,4- Dioxane & 02.22 & 1.421 & 0.021973 & 0.044514 & 0.308001 \\
\hline Acetonitrile & 36.64 & 1.344 & 0.304997 & 0.861037 & 0.664797 \\
\hline Butan-2-ol & 16.6 & 1.397 & 0.262062 & 0.741876 & 0.64075 \\
\hline Chloroform & 04.81 & 1.445 & 0.148553 & 0.37139 & 0.487262 \\
\hline DMF & 38.25 & 1.430 & 0.275352 & 0.83948 & 0.711431 \\
\hline DMSO & 47.24 & 1.479 & 0.263366 & 0.841384 & 0.74447 \\
\hline Ethanol & 24.30 & 1.361 & 0.288592 & 0.811743 & 0.651596 \\
\hline Ethyl acetate & 06.08 & 1.372 & 0.200829 & 0.492671 & 0.499442 \\
\hline Methanol & 33.70 & 1.329 & 0.309015 & 0.857478 & 0.652885 \\
\hline Propan-2-ol & 20.18 & 1.377 & 0.276738 & 0.780731 & 0.646822 \\
\hline Toluene & 02.38 & 1.496 & 0.013504 & 0.02965 & 0.349614 \\
\hline
\end{tabular}


Table 2. Maximum absorption, emission spectra, Stoke shift, and average value of the DPMA molecule.

\begin{tabular}{|l|c|c|c|c|c|c|}
\hline \multicolumn{1}{|c|}{ Solvents } & $\begin{array}{c}\lambda_{a} \\
(\mathrm{~nm})\end{array}$ & $\begin{array}{c}\lambda_{f} \\
(\mathrm{~nm})\end{array}$ & $\overline{v_{a}}\left(\mathrm{~cm}^{-1}\right)$ & $\overline{v_{f}}\left(\mathrm{~cm}^{-1}\right)$ & $\begin{array}{c}\overline{v_{a}}-\overline{v_{f}} \\
\left(\mathrm{~cm}^{-1}\right)\end{array}$ & $\begin{array}{c}\overline{v_{a}}+\overline{v_{f}} \\
2 \\
\left(\mathrm{~cm}^{-1}\right)\end{array}$ \\
\hline $\begin{array}{l}\text { 1,4- } \\
\text { Dioxane }\end{array}$ & 293 & 334 & 34129.69 & 29940.11 & 4189.59 & 32034.9 \\
\hline Acetonitrile & 274 & 330 & 36496.35 & 30303.03 & 6193.32 & 33399.69 \\
\hline Butan-2-ol & 295 & 332 & 33898.30 & 30120.48 & 3777.82 & 32009.39 \\
\hline Chloroform & 294 & 335 & 34013.60 & 29850.74 & 4162.86 & 31932.17 \\
\hline DMF & 274 & 331 & 36496.35 & 30211.48 & 6284.87 & 33353.92 \\
\hline DMSO & 293 & 332 & 34129.69 & 30120.48 & 4009.21 & 32125.09 \\
\hline Ethanol & 293 & 325 & 34129.69 & 30769.23 & 3360.46 & 32449.46 \\
\hline $\begin{array}{l}\text { Ethyl } \\
\text { acetate }\end{array}$ & 293 & 330 & 34129.69 & 30303.03 & 3826.66 & 32216.36 \\
\hline Methanol & 270 & 335 & 37037.03 & 29850.74 & 7186.29 & 33443.89 \\
\hline Propan-2-ol & 253 & 325 & 39525.69 & 30769.23 & 8756.4 & 35147.46 \\
\hline Toluene & 294 & 334 & 34013.60 & 29940.11 & 4073.5 & 31976.86 \\
\hline
\end{tabular}

Table 3. Polarity functions of Lippert, Bakshiev, KCV,empirical state parameter of its slope, intercept, linear correlation coefficient.

\begin{tabular}{|l|c|c|c|c|}
\hline Correlation & Slope $\left(\mathrm{cm}^{-1}\right)$ & Intercept $\left(\mathrm{cm}^{-1}\right)$ & $\begin{array}{l}\text { Correlation } \\
\text { coefficient }(\mathrm{r})\end{array}$ & $\begin{array}{l}\text { Number of } \\
\text { data(n) }\end{array}$ \\
\hline Lippert & 9098.5 & 3249.2 & 0.916 & 7 \\
\hline Bakshiev & 3139.5 & 3562.9 & 0.844 & 7 \\
\hline KCV & 4165.4 & 30436.6 & 0.901 & 7 \\
\hline$E_{T}^{N}$ & 10531.9 & 17726.2 & 0.98 & 11 \\
\hline
\end{tabular}


Table 4. Onsager cavity radius, ground state and excited state dipole moments using polarity functions. (in Debye D)

\begin{tabular}{|l|l|l|l|l|l|c|}
\hline Molecule & $\begin{array}{c}\text { Radius(a) } \\
\mathrm{A}^{0}\end{array}$ & $\begin{array}{c}\mu_{g}^{a} \\
(\mathrm{D})\end{array}$ & $\begin{array}{c}\mu_{e}^{b} \\
\text { (D) }\end{array}$ & $\begin{array}{c}\mu_{e}^{c} \\
(\mathrm{D})\end{array}$ & $\begin{array}{c}\mu_{e}^{d} \\
(\mathrm{D})\end{array}$ & $\begin{array}{c}\mu_{e}^{e} \\
(\mathrm{D})\end{array}$ \\
\hline DPMA & $\mathbf{2 . 7}$ & $\mathbf{0 . 4 0 6}$ & $\mathbf{2 . 8 9 3}$ & $\mathbf{4 . 2 1 8}$ & $\mathbf{2 . 8 8 4}$ & $\mathbf{2 . 8 8 3}$ \\
\hline
\end{tabular}

${ }^{a}$ Ground state dipole moment calculated using Equation (8).

${ }^{\mathrm{b}}$ Excited state dipole moment calculated using Equation (9).

c,d,e Excited state dipole moment calculated using equations Lippert's(5),

Bakshiev's (6) and KCV (7).

Change in dipole moment calculated using Equation (10).

Table 5. The $\mathrm{E}_{\mathrm{T}}(30)$ solvent polarity and $E_{T}^{N}$ normalized solvent polarity of solvents

\begin{tabular}{|l|c|c|c|}
\hline Solvents & $\lambda_{a}(\mathrm{~nm})$ & $\mathrm{E}_{\mathrm{T}}(30)$ & $E_{T}^{N}$ \\
\hline 1,4- Dioxane & 293 & 97.58 & 2.064198 \\
\hline Acetonitrile & 274 & 104.34 & 2.27284 \\
\hline Butan-2-ol & 295 & 96.91 & 2.043519 \\
\hline Chloroform & 294 & 97.24 & 2.053704 \\
\hline DMF & 274 & 104.34 & 2.27284 \\
\hline DMSO & 293 & 97.58 & 2.064198 \\
\hline Ethanol & 293 & 97.580 & 2.064198 \\
\hline Ethyl acetate & 293 & 97.58 & 2.064198 \\
\hline Methanol & 270 & 105.89 & 2.320679 \\
\hline Propan-2-ol & 253 & 113.0 & 2.540123 \\
\hline Toluene & 294 & 97.24 & 2.053704 \\
\hline
\end{tabular}




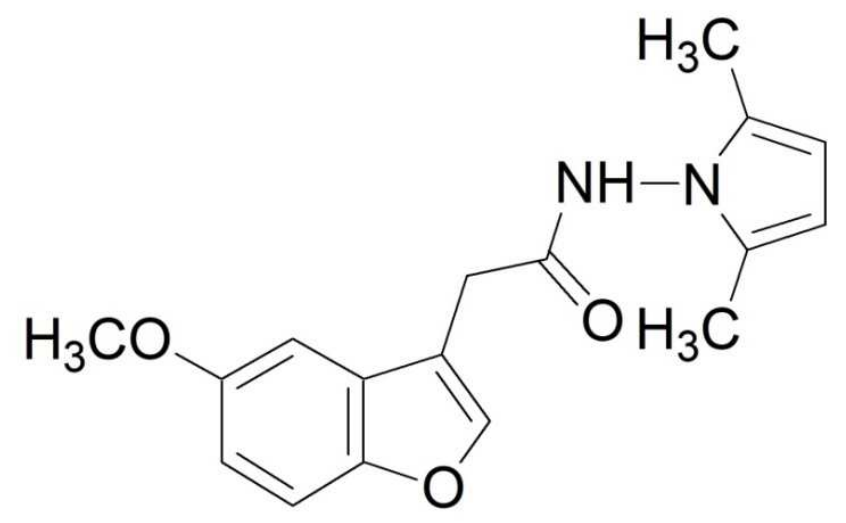

Figure 1 Molecular structure of DPMA Molecule 


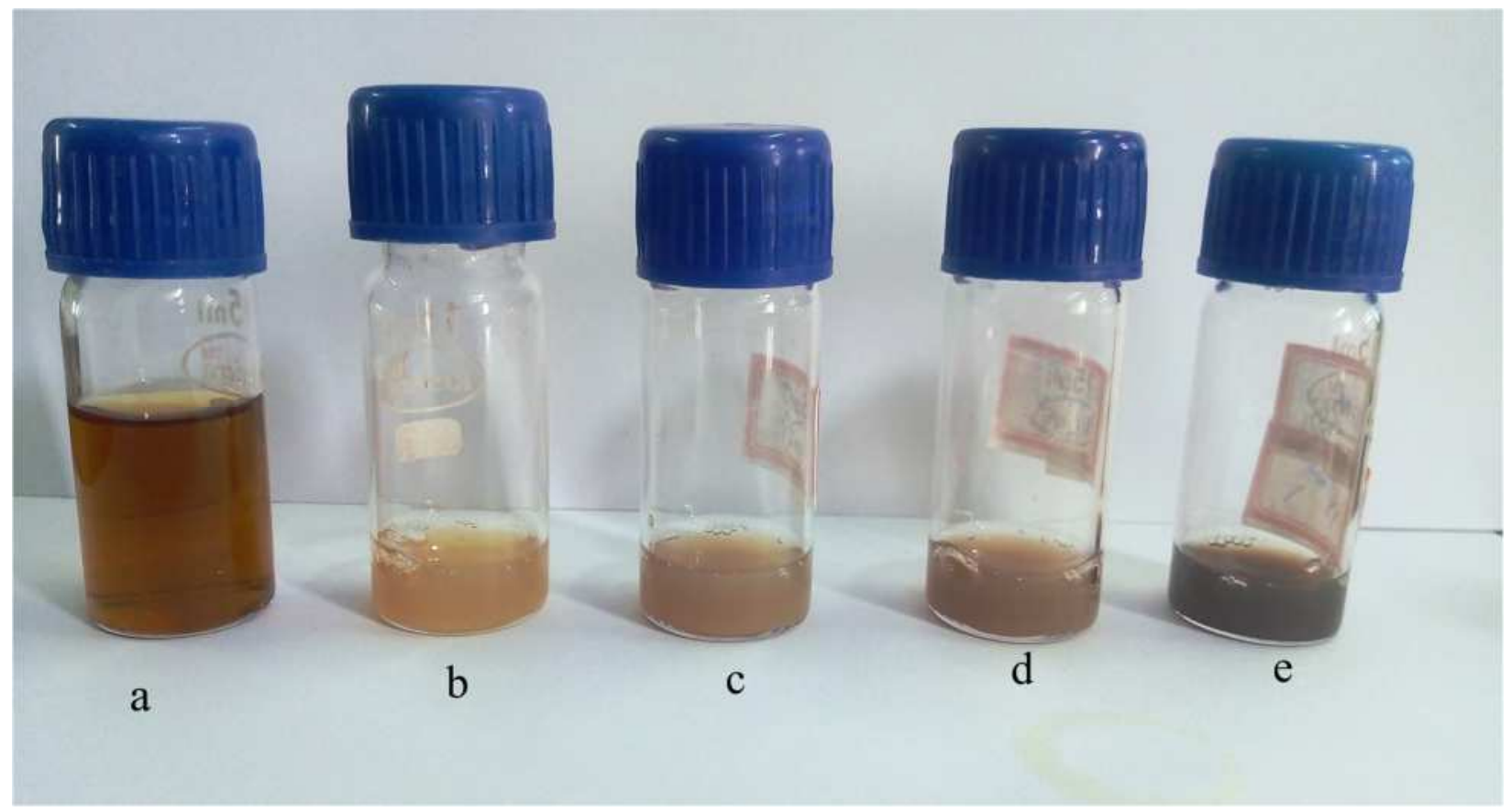

Figure 2 a) C.roseus leaves extract solution b) added AgNO3 solution for 5 minute c) for 10 minute d) for 15 minute d) for 20 minute 
ti

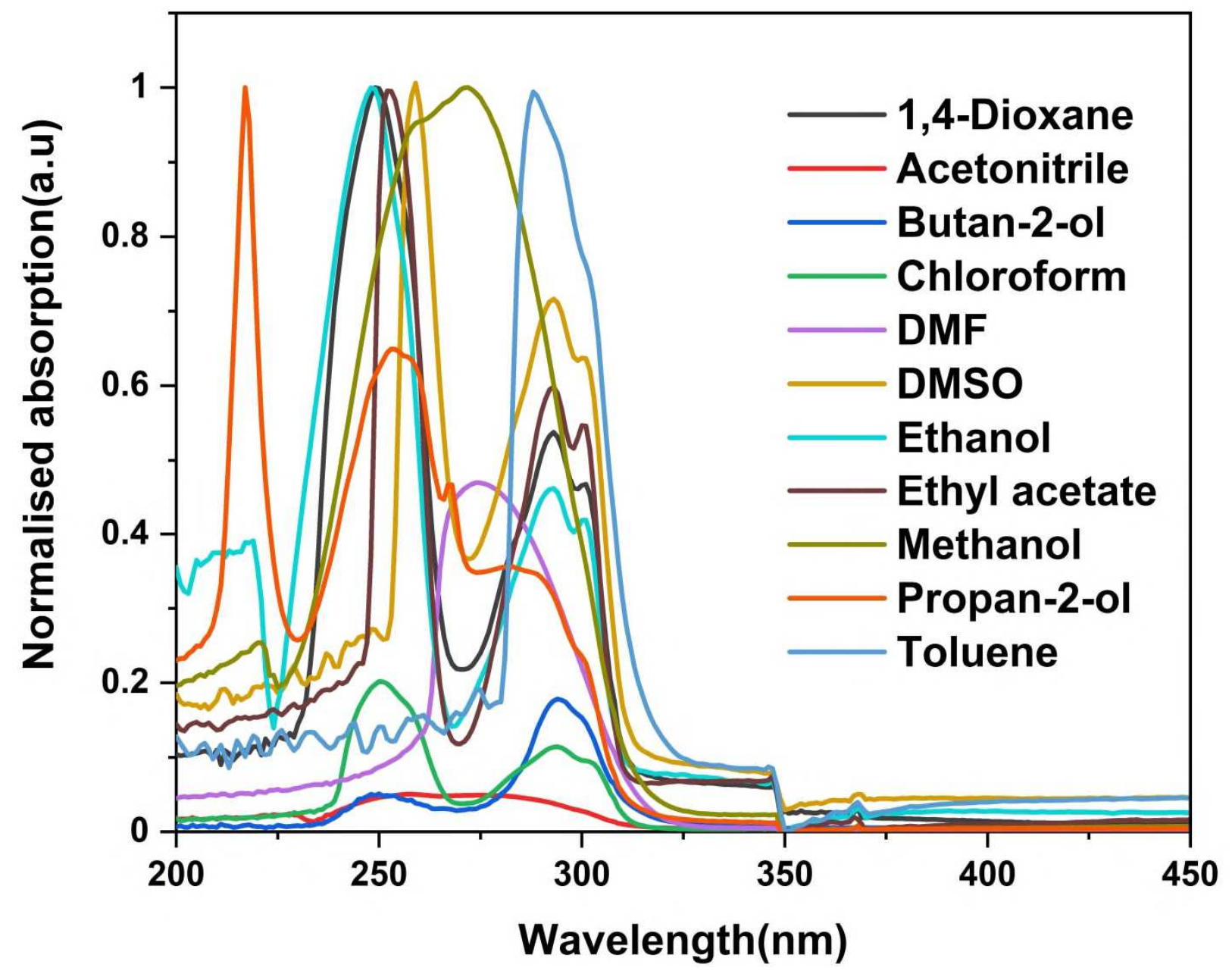

Figure 3 Normalized absorption spectra of DPMA molecule. 


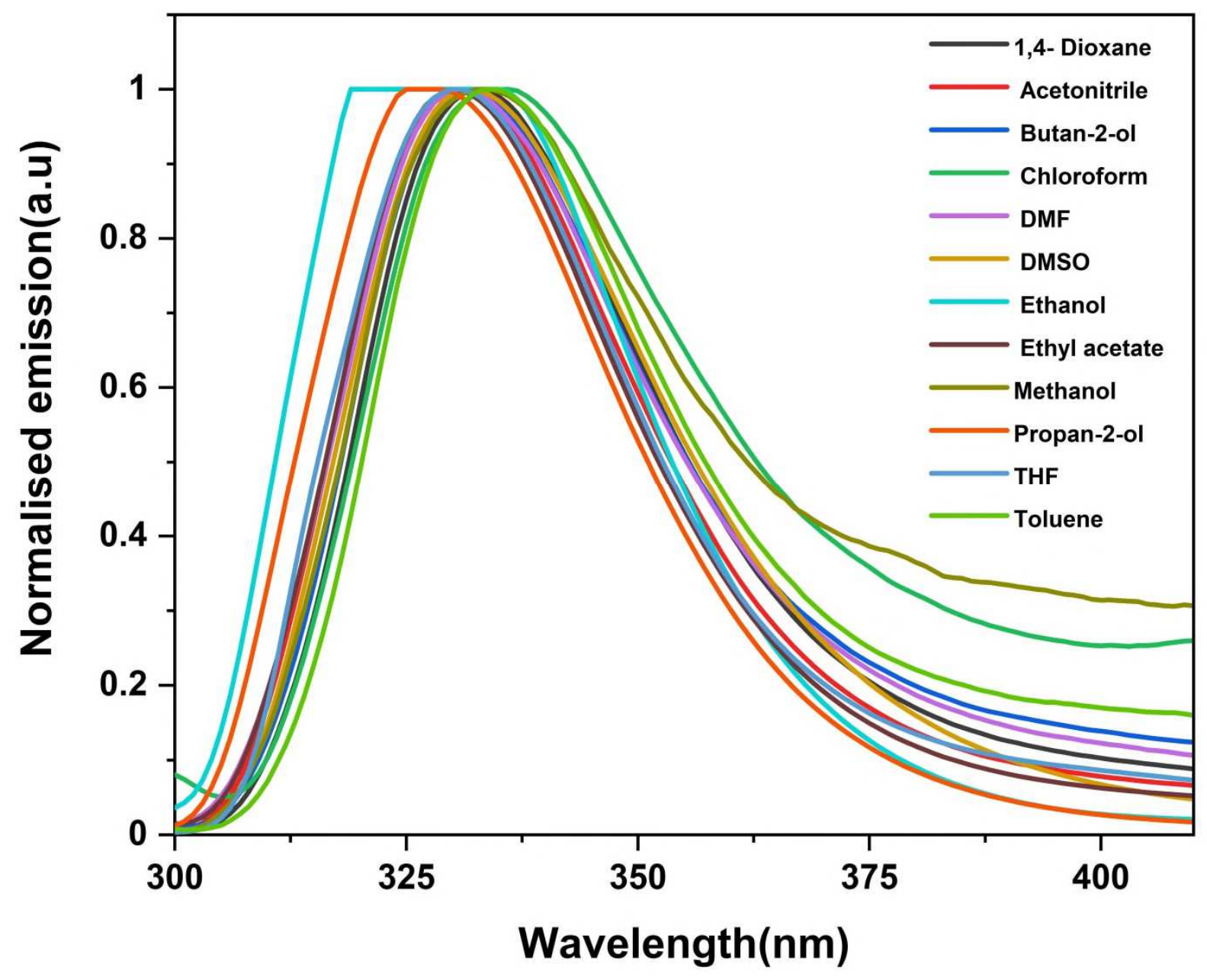

Figure 4 Normalized Emission spectra of DPMA molecule. 


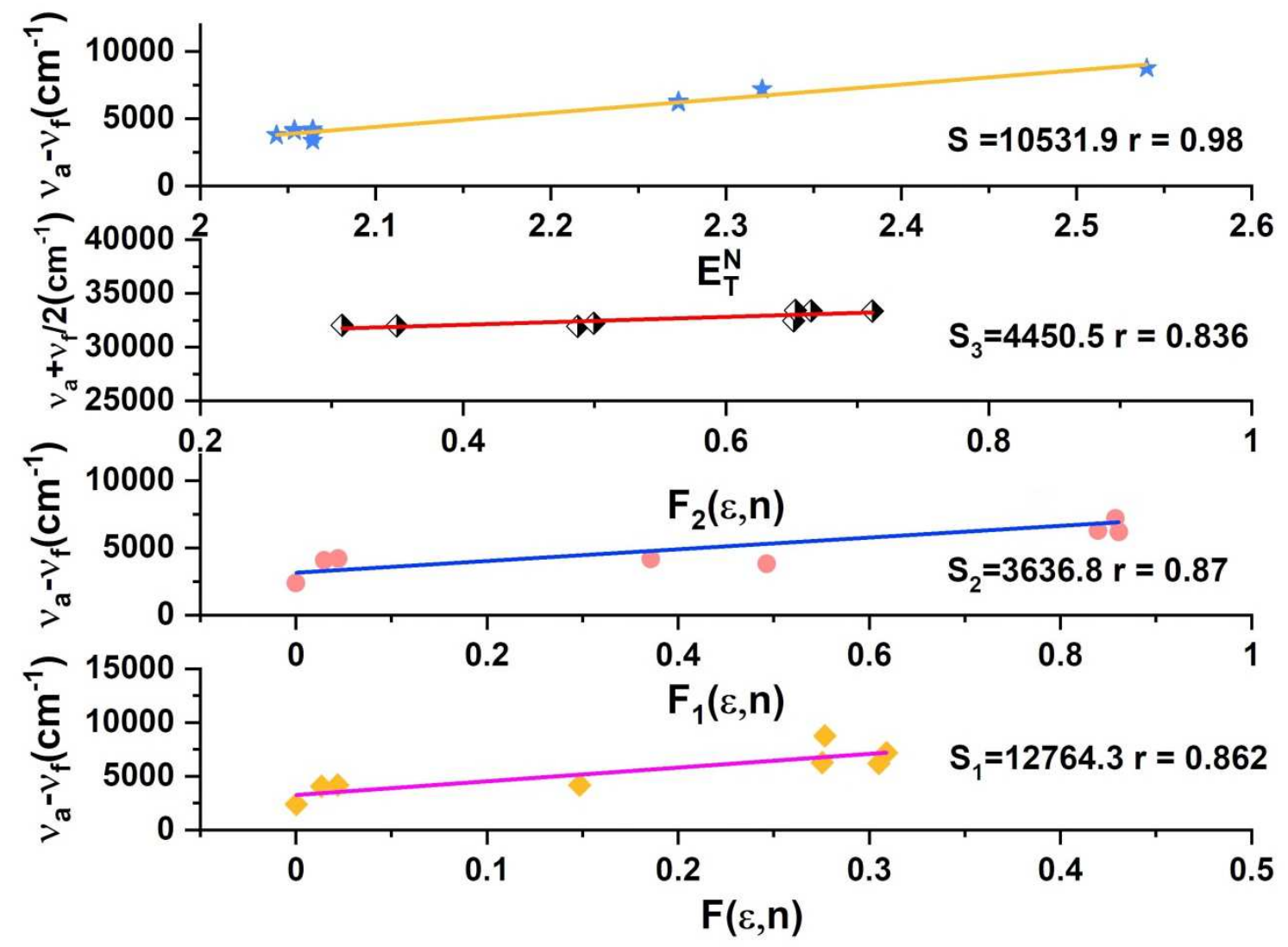

Figure 5. Variation of stoke shift with $\mathbf{E}_{T}^{N}$. Arithmetic mean of wavenumbers with $\mathbf{F}_{2}(\varepsilon, n)$ by Kawski-chamma-Viallet'seqution. The variation of stoke shift with $\mathbf{F}_{1}(\varepsilon, n) \mathbf{u s i n g}$ Bakshiev's equation. The variation of stoke shift with $\mathbf{F}(\varepsilon, n)$ by Lippert's equation. 


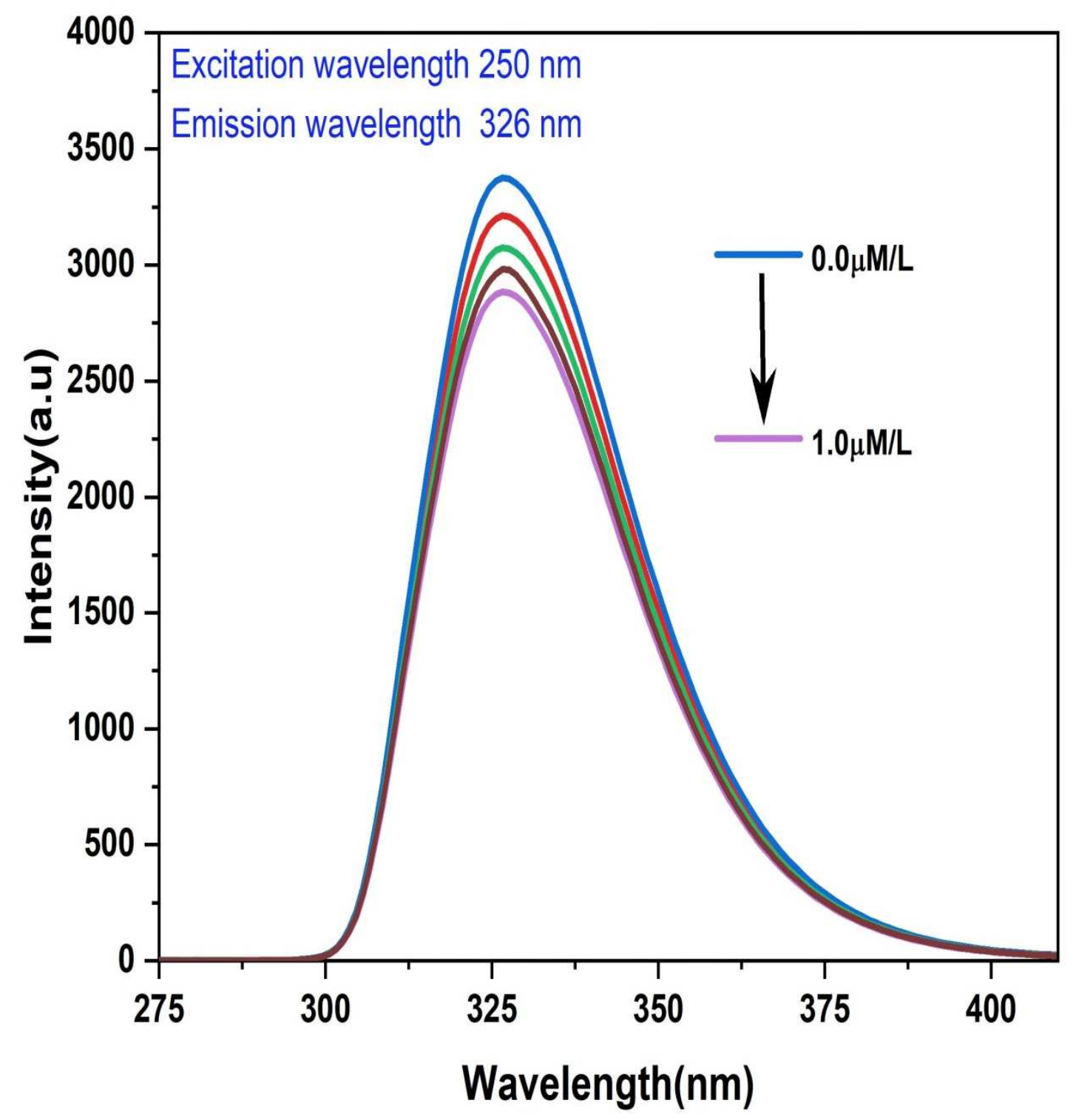

Figure 6 Fluorescence spectra of DPMA molecule in ethanol solvent for different concentration of Ag NPs 


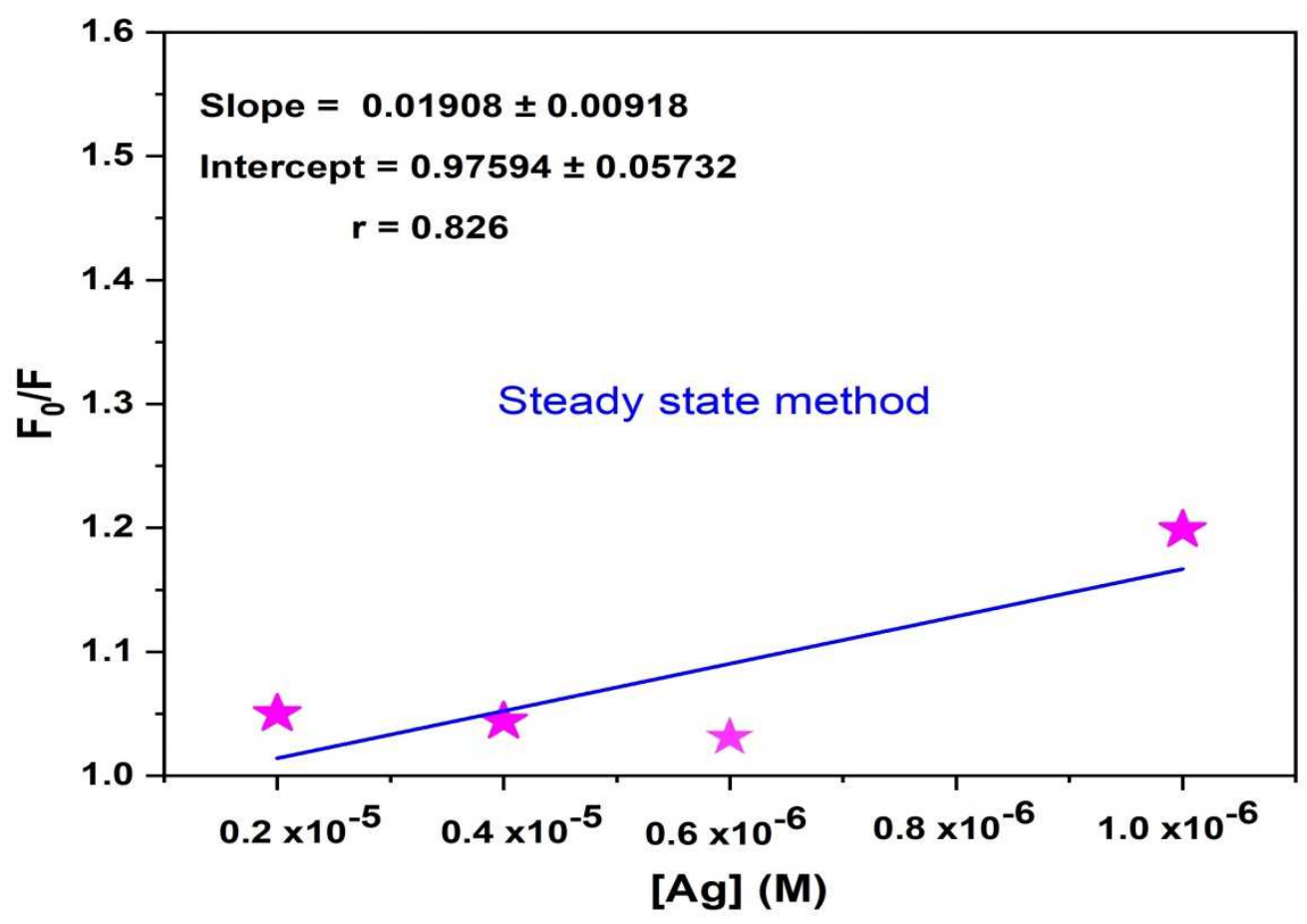

Figure $7 \mathrm{~S}-\mathrm{V}$ plot of DPMA molecule for steady state method 


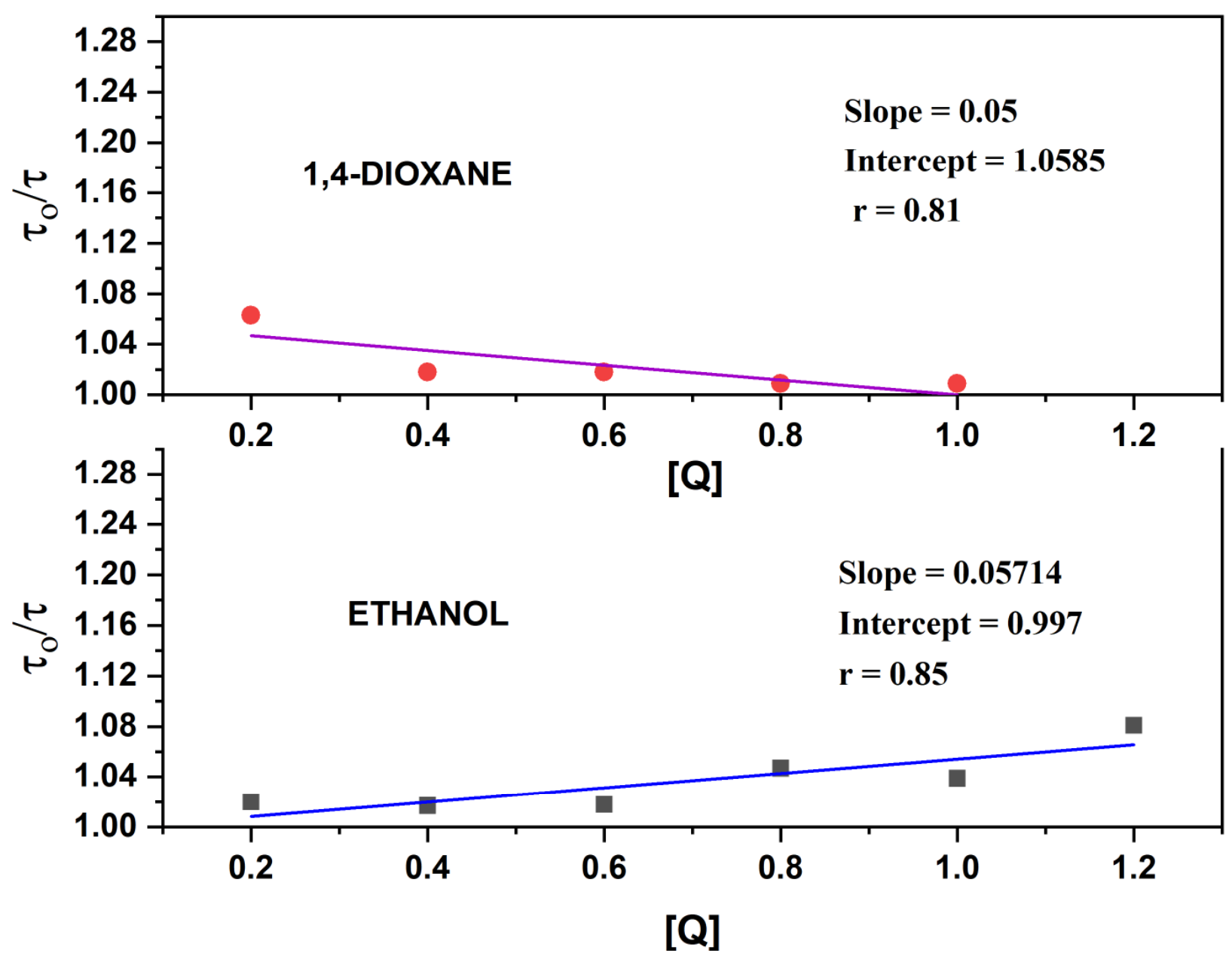

Figure $8 \mathrm{~S}-\mathrm{V}$ plot of DPMA molecule for Transient state method 

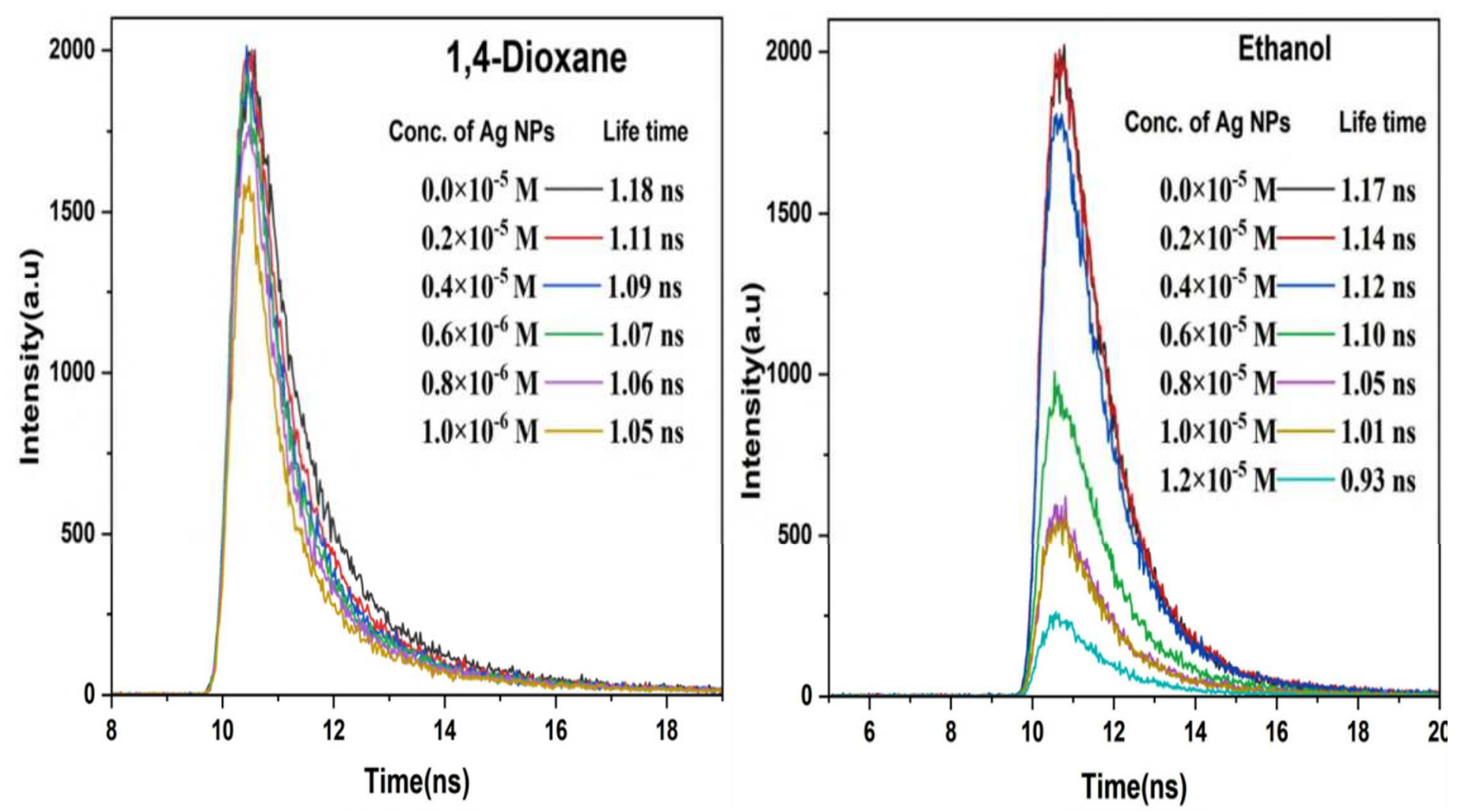

Figure 9. Fluorescence lifetime of DPMA molecule in presence of various Ag NPs Concentration using 1,4-Dioxane and Ethanol solvent 


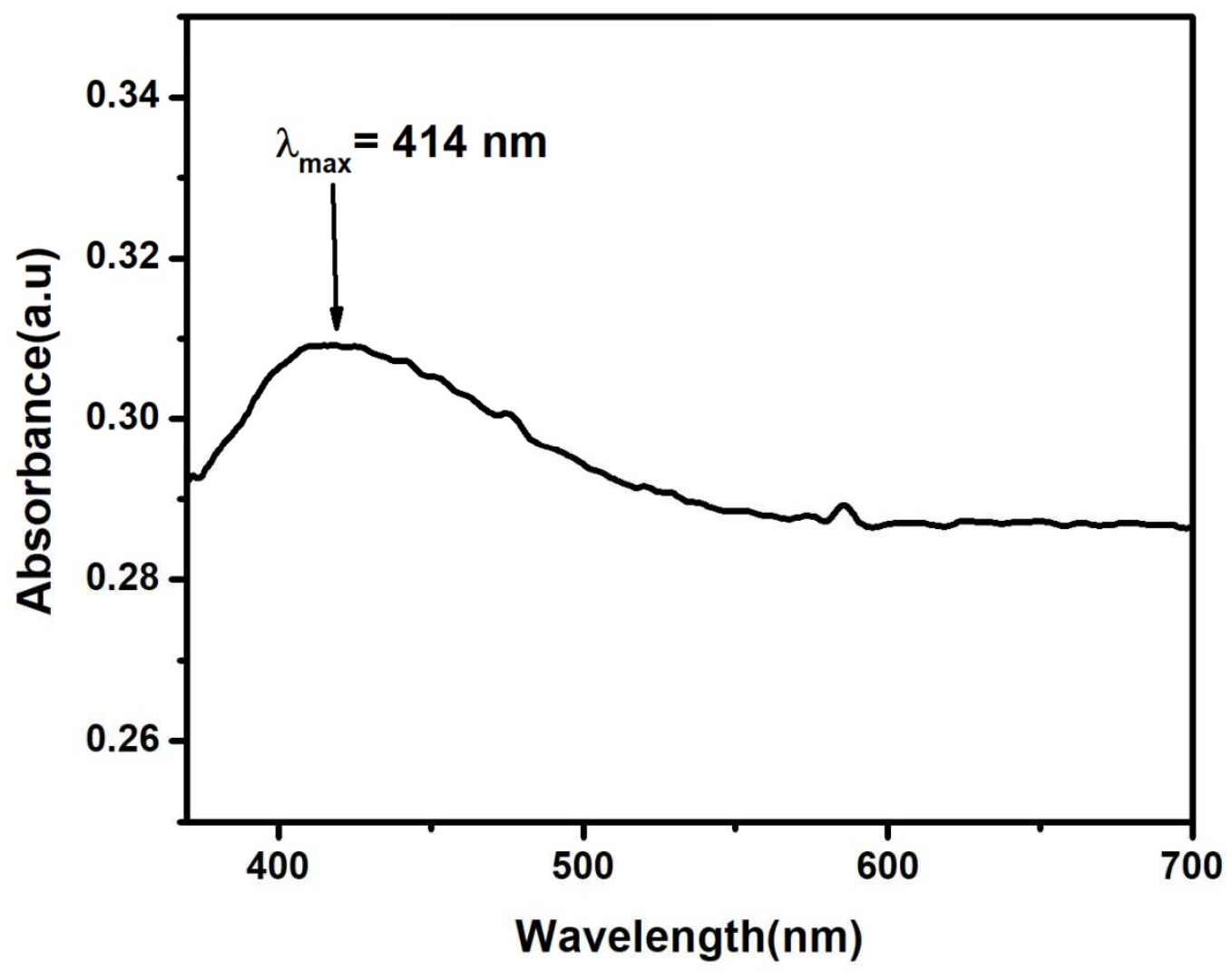

Figure 10 UV-visible spectra of silver NPs in aqueous solution 


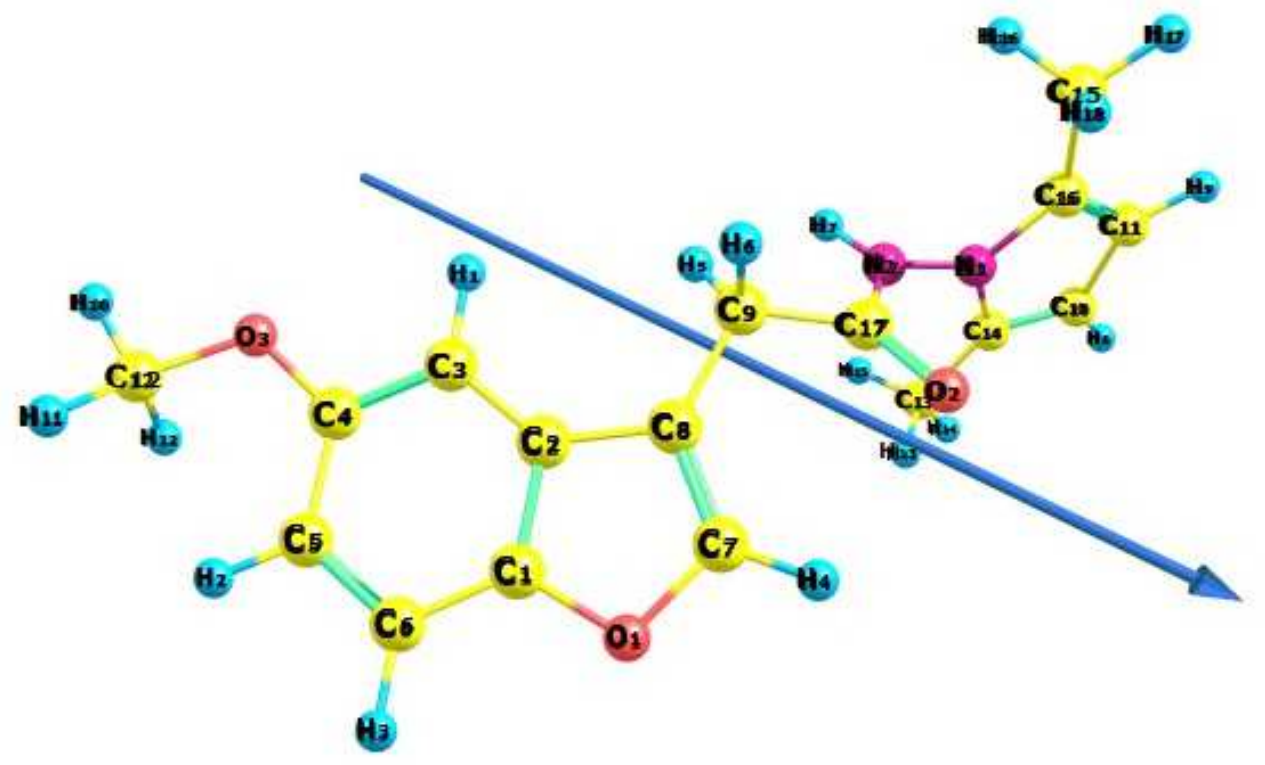

Figure 11 Ground state optimized geometry structure

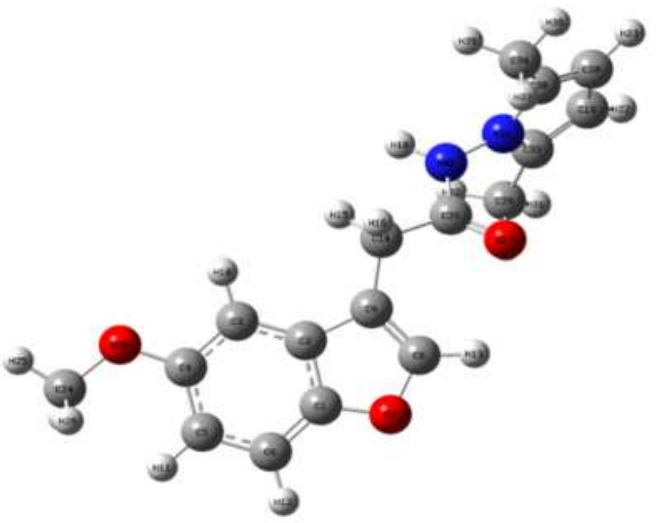

Figure 12 Optimized geometry structure of DPMA molecule 


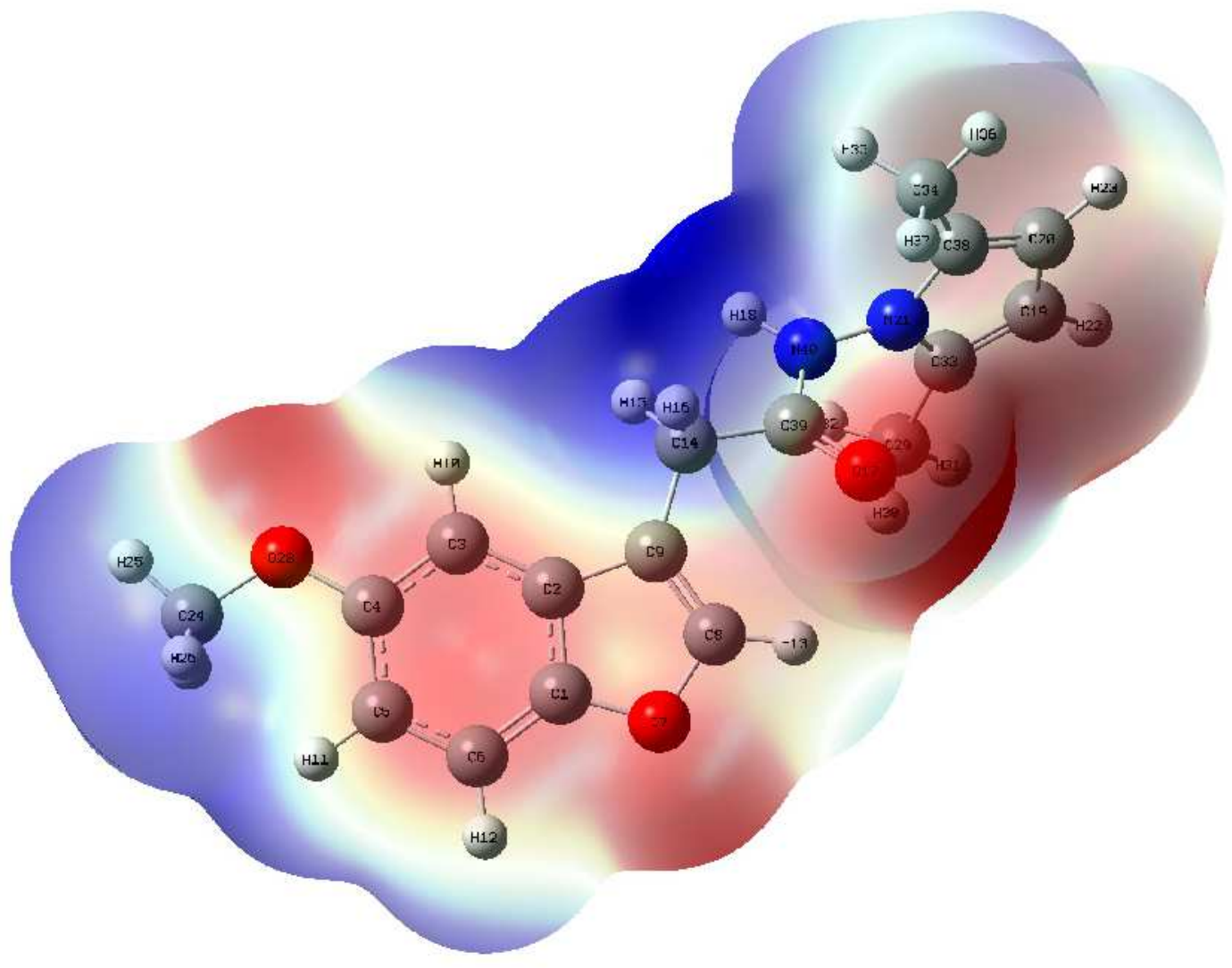

Figure 13 Molecular Electrostatic Potential of DPMA molecule 

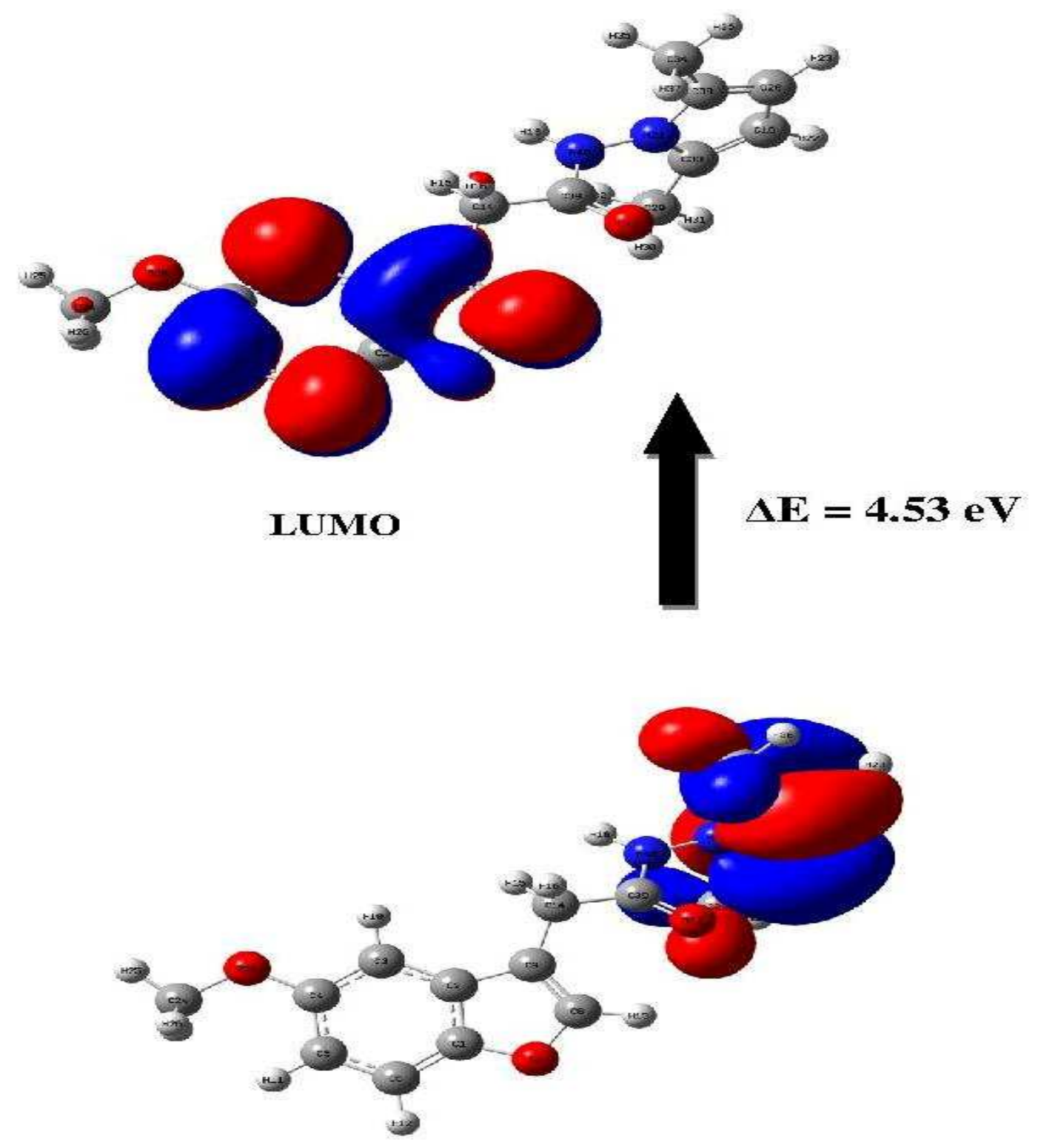

HOMO

Figure 14 HOMO and LUMO structure of DPMA molecule 


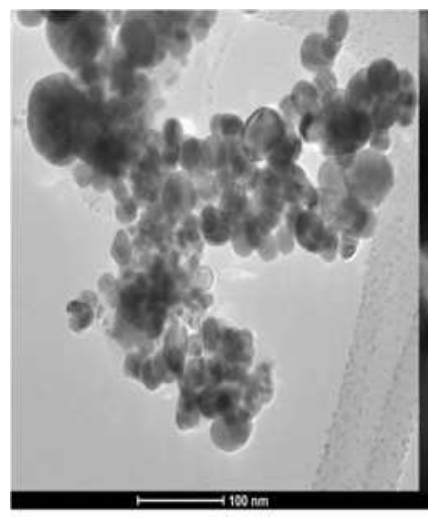

a

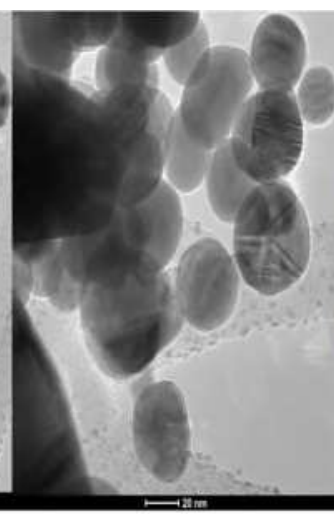

b

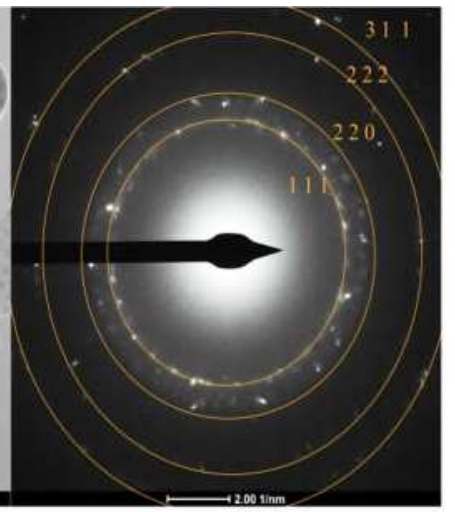

C

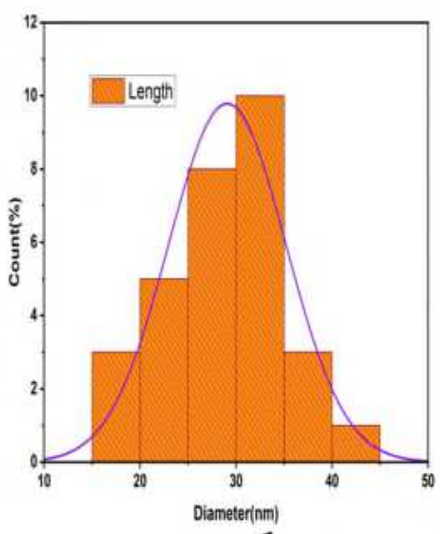

d

Figure 15.TEM images of Ag NPs scale range is a) $100 \mathrm{~nm} \mathrm{b)} 20 \mathrm{~nm}$ c) SAED pattern and d) average diameter of the Ag particle size.

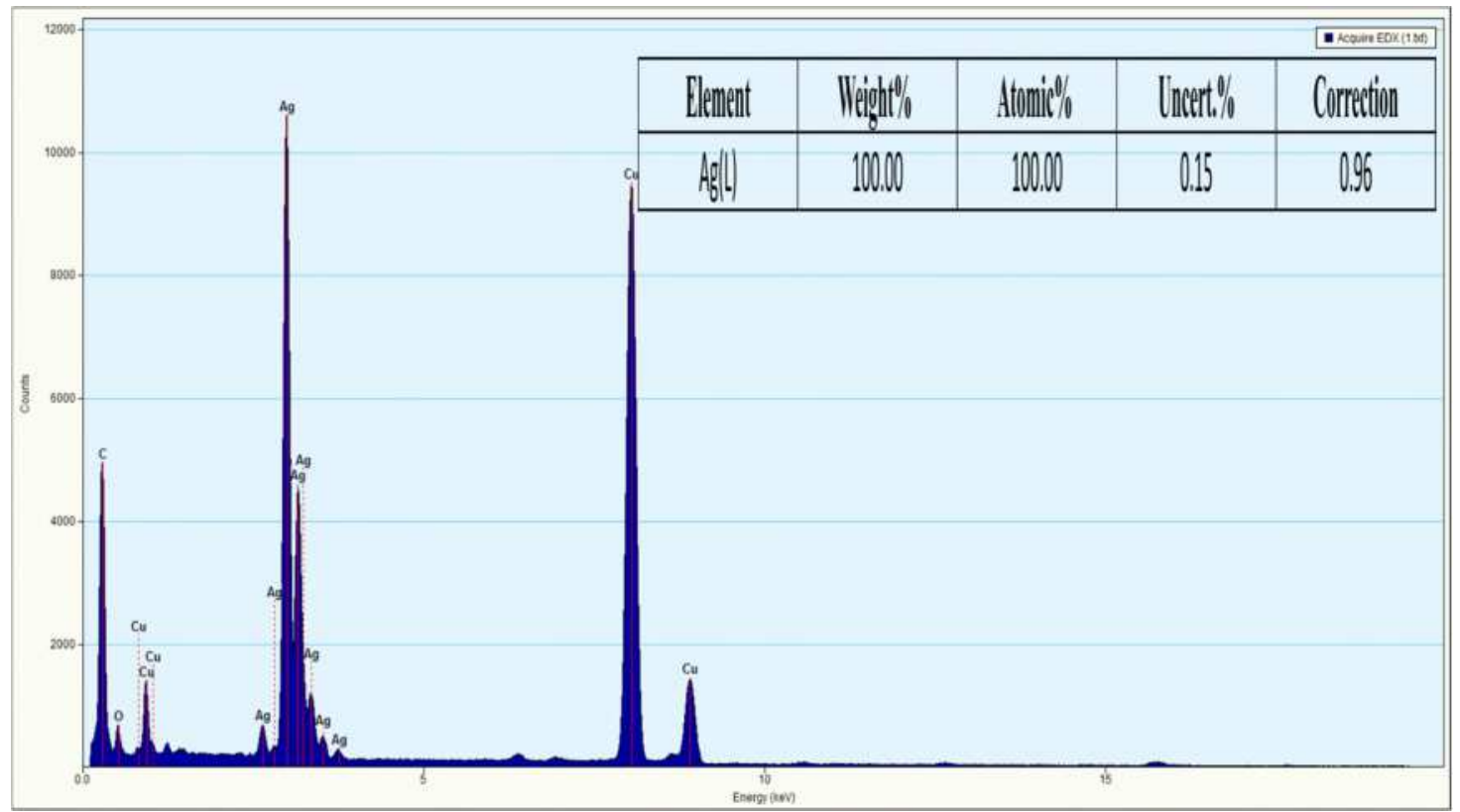

Figure 16. Elemental mapping TEM- EDX Spectrum of Ag NPs 


\section{Supplementary Files}

This is a list of supplementary files associated with this preprint. Click to download.

- Graphicalabstract.docx 